$12-9-2013$

\title{
Learning, Active Investors, and the Returns of Financially Distressed Firms
}

Christian C. Opp

University of Pennsylvania

Follow this and additional works at: https://repository.upenn.edu/fnce_papers

Part of the Finance and Financial Management Commons

\section{Recommended Citation}

Opp, C. C. (2013). Learning, Active Investors, and the Returns of Financially Distressed Firms. Retrieved from https://repository.upenn.edu/fnce_papers/16

This paper is posted at ScholarlyCommons. https://repository.upenn.edu/fnce_papers/16

For more information, please contact repository@pobox.upenn.edu. 


\title{
Learning, Active Investors, and the Returns of Financially Distressed Firms
}

\author{
Abstract \\ I develop an analytically tractable dynamic asset pricing model to study expected returns of financially \\ distressed firms in the presence of learning about firm fundamentals and endogenous information \\ acquisition by active investors. The model reveals that learning and information acquisition critically \\ affect lowfrequency risk exposures close to default and can, counter to standard models, rationalize low \\ and even negative expected return premia for firms with high default risk. Similar to Schumpeter's (1934) \\ argument that recessions have a positive, cleansing effect on the economy, the model reveals that equity \\ holders naturally benefit from an increased speed of learning about truly insolvent firms in downturns, \\ which positively affects the value of their default option in these times. Equity holders' option value is \\ similarly enhanced by the ability to partially freeride on active investors' information acquisition. Learning \\ thus dynamically affects distressed firms' exposures to business-cycle frequency risks and can \\ rationalize striking, momentum-type dynamics in risk premia.

\section{Keywords} \\ expected returns, financial distress, learning, information acquisition, momentum, active investors, private \\ investments in public equity \\ Disciplines \\ Finance and Financial Management
}




\title{
Learning, Active Investors, and the Returns of Financially Distressed Firms
}

\author{
Christian C. G. Opp*
}

December 9, 2013

\begin{abstract}
I develop an analytically tractable dynamic asset pricing model to study expected returns of financially distressed firms in the presence of learning about firm fundamentals and endogenous information acquisition by active investors. The model reveals that learning and information acquisition critically affect lowfrequency risk exposures close to default and can, counter to standard models, rationalize low and even negative expected return premia for firms with high default risk. Similar to Schumpeter s (1934) argument that recessions have a positive, cleansing effect on the economy, the model reveals that equity holders naturally benefit from an increased speed of learning about truly insolvent firms in downturns, which positively affects the value of their default option in these times. Equity holders' option value is similarly enhanced by the ability to partially freeride on active investors' information acquisition. Learning thus dynamically affects distressed firms' exposures to business-cycle frequency risks and can rationalize striking, momentum-type dynamics in risk premia.
\end{abstract}

Keywords: Expected Returns, Financial Distress, Learning, Information Acquisition, Momentum, Active Investors, Private Investments in Public Equity

${ }^{*}$ The Wharton School, University of Pennsylvania. Email: opp@wharton.upenn.edu. This paper was previously circulated under the title "The Effect of Learning on Equity Returns in Financial Distress". I am grateful for comments and suggestions from Hui Chen, Alex Edmans, Dirk Hackbarth, Alan Moreira, Paul Pfleiderer, Matt Spiegel, Ilya Strebulaev and from seminar participants at the Wharton School, Yale School of Management, UT Austin, University of Notre Dame, Stanford GSB, the 2012 WFAs, and the Kellogg Junior Finance Conference. Research support from the Marshall Blume Prize in Financial Research, the Rodney White Center for Financial Research, and the Wharton School Dean's Research Fund is gratefully acknowledged. 


\section{Introduction}

"After all, you only find out who is swimming naked when the tide goes out." Warren Buffett in the letter to shareholders (2001).

Measures of default risk predict low future stock returns (Dichev, 1998, Campbell, Hilscher, and Szilagyi, 2008) - this empirical finding has given rise to the so-called "distress anomaly," since standard models suggest that the equity of firms with high default risk is more exposed to aggregate risk and therefore should command higher expected returns. Recently, Park (2013) sheds more light on this finding by documenting that low returns on financially distressed stocks are concentrated among firms that issue discounted equity to new investors via private offerings of public equity that dilute existing shareholders. Although intriguing, these findings do not per se resolve the distress puzzle since existing investors may use default risk measures to predict dilution and thus should appropriately adjust prices for expected dilution. Additionally, proximity to default appears to play an important role for momentum returns, since momentum profits are restricted to high credit risk firms and are nonexistent for firms of high credit quality, as documented by Avramov, Chordia, Jostova, and Philipov (2007). In this paper, I develop a dynamic asset pricing model that proposes two related channels that can reconcile these empirical facts based on investors' rational formation of beliefs about distressed firm's chances of future recovery: first, passive learning from firm performance, and secondly, active investors' information acquisition and its externality on other investors.

The first channel, learning from firm performance, is related to Schumpeter's (1934) argument that recessions have a positive, "cleansing effect" on the economy. Equity holders benefit in aggregate downturns from a high speed of learning about illiquid firms' chances of future recovery. When exposed to the test of a downturn, truly insolvent firms are more likely to show adverse performance that allows equity holders to separate them from solvent but illiquid firms. Executing their default option in the case of insolvent firms then allows equity holders to quickly limit their losses from subsidizing debt holders. Learning about firm solvency thus positively affects equity holders' default option value in aggregate downturns, thereby reducing distressed firms' exposure to businesscycle frequency risks. These low-frequency risks are in turn major determinants of risk premia when investors have recursive preferences ${ }^{1}$ as emphasized by the long-run risk literature (Bansal and Yaron, 2004, Hansen, Heaton, and Li, 2008).2 The analysis re-

\footnotetext{
${ }^{1}$ See Kreps and Porteus (1978), Epstein and Zin (1989), Weil (1990).

${ }^{2}$ The quality of information is not to be confused with the physical uncertainty of the underlying earnings process. Increased uncertainty about the underlying naturally increases the value of the option.
} 
veals that the proposed learning channel can even rationalize negative equity risk premia for distressed firms that have strongly pro-cyclical underlying earnings dynamics. Further, the theory can explain why portfolios consisting of the most financially distressed stocks would obtain negative unconditional alpha estimates. As the quintile of stocks with the most financially distressed stocks is closer to default in downturns, learning has a stronger positive effect on the corresponding portfolio value, implying lower conditional betas with respect to long-run risks and lower expected returns in these times. Importantly, the resulting negative correlation between market risk premia and conditional betas implies upward biased beta estimates and negatively biased alpha estimates in standard unconditional CAPM regressions ${ }^{3}$ This prediction is supported by recent empirical evidence by O'Doherty (2012) who finds that the correlation between market risk premia and conditional betas of distressed stocks accounts for about two thirds of the negative unconditional alpha of financially distressed firms.

The model further sheds light on the empirical finding by Avramov, Chordia, Jostova, and Philipov (2007) that momentum profits are restricted to high credit risk firms and are nonexistent for firms of high credit quality. Positive correlations between price changes and expected returns obtain, since firms that receive bad news and get closer to the default boundary also have lower expected return premia going forward. A momentum strategy that goes long recent winners and shorts recent losers among distressed firms can therefore generate a large spread in expected returns. Consistent with this theoretical argument, Avramov, Chordia, Jostova, and Philipov (2007) find that both the extreme loser and winner portfolios consist of stocks with the lowest and the next-lowest credit rating, respectively.

The second channel of the model is also related to learning and highlights an externality that has previously not been studied in the the dynamic asset pricing literature: active investors' effect on other claim holders' exposure to aggregate risk via their impact on the firm's refinancing and liquidation decisions. Active investors (for example, activist hedge funds or private equity funds) typically acquire substantial stakes in distressed firms' private placements of public equity. In the model, these specialized investors may exert costly effort to acquire information on distressed firms' chances of future recovery. Management endogenously issues equity to one such investor when the firm becomes illiquid and existing investors are uncertain whether the firm is fundamentally solvent 4 Providing one investor with a large equity stake helps resolve a standard free-rider prob-

\footnotetext{
${ }^{3}$ See, e.g., Grant (1977) and Jagannathan and Wang (1996).

${ }^{4}$ Brophy, Ouimet, and Sialm (2009) document that hedge funds tend to finance companies that have poor fundamentals and pronounced informational frictions, and require substantial discounts.
} 
lem present among small investors (see, e.g., Grossman and Hart (1980) and Shleifer and Vishny (1986)). The large investor has strictly greater incentives to acquire costly information that helps identifying insolvent firms and avoids implicit subsidies to debt holders. Existing shareholders can partially free ride on the active investor's effort going forward and thus are willing to provide the active investor initially with a discounted purchase price, that is, a price lower than the equilibrium market value of the stake obtained. Due to its superior information, the active investor assumes a pivotal role in the firm's future liquidation and refinancing decisions which affect the value of all equity holders, thus creating an externality.

The active investor's involvement helps resolve debt overhang problems (Myers, 1977) that are typical for firms close to default. Better information about a firm's future performance has the positive effect of avoiding unnecessary defaults by firms that are merely temporarily illiquid but fundamentally solvent. Yet better information also has redistributional effects. In particular, debt holders of insolvent firms are ceteris paribus worse off, since better informed equity holders quickly abandon insolvent firms, and thus stop subsidizing debt holders via equity injections. The analysis shows that although endogenous information acquisition can have similarly adverse effects on debt holders as risk shifting (Jensen and Meckling, 1976), it does not require any change in the underlying assets or in contracts.

Importantly, active investor's information acquisition not only affects expected cash flows but also the risk exposures of debt and equity claims. Since the speed of learning influences valuations across aggregate states of the economy, information production can shift aggregate risk from equity to debt claims. If learning based on a firm's public information is slow in aggregate downturns, the active investor has a natural incentive to increase the speed of learning in these times, which allows off-loading systematic risk to debt holders. Since passive shareholders do not incur information acquisition cost on an ongoing basis, their equity stakes are even less exposed to aggregate risk than the active investor's position. This mechanism provides an explanation for the puzzling empirical phenomenon that buy-and-hold returns after private offerings of public equity are low and negatively correlated with the discounts that are provided to the large investors that participate in these offerings (Park, 2013). In addition, the results shed light on the general empirical finding that public companies that raise equity privately from large specialized investors such as hedge funds significantly underperform companies that obtain financing from other investors in the future (Brophy, Ouimet, and Sialm, 2009). In the model, management is willing to offer larger discounts to active investors 
with greater skill. A larger discount thus forecasts more effective involvement of the active investor going forward, and thus a stronger effect on the equity's exposure to aggregate risk. In other words, the involvement of an active investor is a state variable that affects distressed firms' conditional exposures to business-cycle frequency risks.

The model further reveals that negative contemporaneous returns for existing shareholders at the time when the active investor acquires shares at a discount are not conclusive evidence that management is acting against shareholders' interests. By conditioning on firms that issue discounted equity to an active investor, the econometrician systematically sorts on firms that just received a negative shock and for that reason approach an active investor. In other words, under the counter-factual without active investor involvement, existing equity holders' position would lose at least as much value. Since existing shareholders gain from free riding on the active investor's information production going forward, management is willing to provide the fund attractive terms ex ante - in the limiting case in which the active investor has all the bargaining power, existing shareholders are just as well off with and without discounted equity issuance.

Related literature. This paper is generally related to a growing literature on learning in financial markets (see Pastor and Veronesi (2009) for a survey) and the relationship between financing decisions and asset pricing.5 Gomes and Schmid (2010) for example analyze the relationship between leverage and expected stock returns in a dynamic economy where here both corporate investment and financing decisions are endogenous. The authors show that firms with higher leverage are typically also more mature firms with fewer risky growth opportunities which shows the importance of controlling for the interdependence of leverage and investment decisions when studying the cross-section of expected returns. In terms of model ingredients the paper closest to mine is David (2008) who analyses credit spreads in a dynamic economy with learning. Whereas in David (2008) agents learn about the hidden drifts of real earnings growth and inflation (both log-normal processes), I consider a setting in which agents learn about a hidden firm-specific state that determines the firm's transition rates between earnings states. The benefit of the setup I propose is that it allows me to solve for the endogenous default boundaries which are key to obtaining the main results of my paper. In contrast, David (2008) has to make exogenous assumptions on the default boundaries in his setting in order to solve for prices. To my knowledge, my paper is the first to characterize endoge-

\footnotetext{
${ }^{5}$ See, e.g., Hackbarth, Miao, and Morellec (2006), Livdan, Sapriza, and Zhang (2009), Chen (2010), Bhamra, Kuehn, and Strebulaev (2010), and Gomes and Schmid (2010).
} 
nous default boundaries in a dynamic model with learning and leverage. In addition, my paper not only considers passive learning but also endogenous dynamic information acquisition.

My paper's main objective is to provide a tractable model that illustrates the profound effects that learning and information acquisition have on financially distressed firms' business-cycle frequency risk exposures. I do not attempt to argue that learning is the only plausible mechanism that can help explain the distress anomaly or the other empirical facts addressed in this paper. For example, investor irrationality can certainly contribute toward these anomalies. However, agents' learning about firms solvency over the business cycle seems to be a generically relevant economic force that has its roots in business cycle theory going back to Schumpeter's (1934) famous "cleansing effect of recessions" and that can enrich our understanding of the risk characteristics of financially distressed firms.

Regarding the distress anomaly, complementary theoretical explanations have been put forward in the literature that have other virtues and limitations. George and Hwang (2010) argue that firms with high financial distress costs choose low leverage to avoid distress but retain exposure to the systematic risk of bearing such costs in low states, implying that they have higher expected returns than highly levered firms. Garlappi and Yan (2011) provide a model that shows how potential shareholder recovery upon resolution of financial distress (violation of the absolute priority rule) may effectively imply de-levering upon default, which may account for lower expected returns for firms with high default probabilities. Similarly, Garlappi, Shu, and Yan (2008) argue that bargaining between equity holders and debt holders in default may account for low expected equity returns on firms with high default risk given that shareholders can extract high benefits from renegotiation ${ }^{6}$ McQuade (2013) provides a model in which financially distressed stocks have low equity risk premia since equity, due to its optionality, can be negatively exposed to a volatility risk factor. In contrast to my paper, these papers do not consider the effects of learning on expected equity returns of distressed firms and do not address the empirical finding that low returns on financially distressed stocks are concentrated among those firms that issue discounted equity in private placements. Further, these papers only provide an explanation why financially distressed firms should have low expected returns. They do not resolve the puzzle why CAPM or factor model regressions

\footnotetext{
${ }^{6}$ Hackbarth, Haselmann, and Schoenherr (2013) provide evidence that weaker creditor rights are associated with lower equity risk premia for distressed firms. However, their evidence does not address the distress anomaly, since it cannot explain why the CAPM and the three factor model yield negative alphas for financially distressed firms.
} 
would fail to correctly capture true risk exposures of distressed firms and produce the negative alphas. Ozdagli (2013) emphasizes that risk under the physical and risk-neutral measure do not need to coincide, implying that the equity of firms with high physical default risk does not need to command high risk premia. Consistent with this general idea, I provide a learning-based economic rationale for why financially distressed firms should indeed have low exposures to priced risk despite their high physical default risk. In addressing the momentum anomaly but not the distress puzzle, Sagi and Seasholes (2007) argue that a firm's revenues, costs, and growth options jointly account for dynamics in return autocorrelation, and that account for these effects allows for enhanced momentum strategies. Johnson (2002) provides an alternative rational explanation of momentum effects based on stochastic expected growth rates that is also unrelated to financial distress.

Several empirical papers analyze the relationship between private placements and equity returns. Consistent with Park (2013), Krishnamurthy, Spindt, Subramaniam, and Woidtke (2005) find that shareholders not participating in private placements experience post-issue negative long-term abnormal returns. Based on my model, I argue that these low returns may be rationalized by changes in conditional betas that occur with the change in information quality due to private placements that involve specialized investors such as hedge funds. Hertzel, Lemmon, Linck, and Rees (2002) also document that public firms that place equity privately experience negative post-announcement stockprice performance. Hertzel and Smith (1993) provide empirical evidence that discounts provided in private placements reflect information costs borne by private investors, which is consistent with the mechanism in my model. Vassalou and Xing (2004) document that the size effect in expected returns exists only in segments of the market with high default risk, and that this is also largely the case for the book-to-market effect. Vassalou and Xing (2004) further find some evidence that distressed stocks with a low distance to default have higher returns, but this evidence comes entirely from small value stocks. Da and Gao (2010) further provide evidence that distressed firms' stock returns in Vassalou and Xing (2004) are biased upwards by 1-month reversal and bid-ask bounce. Griffin and Lemmon (2002) document that among firms with the highest distress risk the difference in returns between high and low book-to-market securities is more than twice as large as that in other firms. Further, the authors find that firms with high distress risk exhibit the largest return reversals around earnings announcements. Gao, Parsons, and Shen (2013) provide further evidence on the robustness of the distress anomaly based on a broad international data set of 39 countries. The authors find that the distress anomaly is not related to a country's creditor protection environment, which is inconsistent with 
theories based on shareholder expropriation. Gao, Parsons, and Shen (2013) further find that the distress anomaly is especially strong in North America and Europe, that is, developed financial markets, where active investors may play a more important role in generating the effects highlighted in this paper.

In the following, I first present a baseline model that features learning from firm performance. In section 3, I extend the setup to incorporate an active investor. Sector 4 concludes.

\section{The Baseline Model}

\subsection{Preferences and Technology}

I consider a Lucas-Breeden economy, where aggregate consumption dynamics are specified exogenously and analyze pricing implications for marginal firms. The economy is in continuous time and admits a representative household. Let $C_{t}$ denote the rate of aggregate consumption in the economy at time $t$, which follows the proces: $\mathbf{t}^{7}$

$$
\frac{d C(t)}{C(t)}=\theta\left(Z_{t}\right) d t
$$

The state variable $Z_{t}$ governs dynamics in the growth rate of aggregate consumption $\theta\left(Z_{t}\right)$ and can also affect preferences parameters, as further described below. I assume that $Z_{t}$ follows a two-state continuous time Markov chain with $Z \in\{G, B\}$, where $G$ refers to a high growth state and $B$ refers to a low growth state. By considering a larger number of states, the model can in principle capture rich dynamics in consumption growth. Yet, for the purposes of this paper, I will focus on the case of two aggregate states, which suffices to highlight the central points of the argument and increases analytical tractability and transparency of the results. I denote the transition rate between aggregate state $Z$ and $Z^{\prime}$ by $\lambda(Z)$.

The representative household has the continuous-time version of state-dependent recursive preferences considered in Melino and Yang (2003). These generalized recursive preferences are a useful tool to ensure counter-cyclical aggregate risk premia in an economy where consumption growth follows the simple two-state process considered above.

\footnotetext{
${ }^{7}$ In the following, all processes will be right continuous with left limits. Given a process $y_{t}$, the notation $y_{t-}$ will denote $\lim _{s \uparrow t} y_{s}$, whereas $y_{t}$ denotes $\lim _{s \downarrow t} y_{s}$.
} 
In contrast, standard recursive preferences have the shortcoming that risk premia on a claim to aggregate consumption are generally pro-cyclical in such an environment. The only purpose of allowing for state-dependent preferences in the model is to show that the highlighted risk-premia dynamics for financially distressed firms do not depend on specific aggregate risk premia dynamics and robustly arise when aggregate risk premia are counter-cyclical, which is the empirically plausible case.

The representative household maximizes

$$
J_{t}=E_{t}\left[\int_{t}^{\infty} f\left(C_{\tau}, J_{\tau}\right) d \tau\right]
$$

where $f(C, J)$ is a normalized aggregator of current consumption $C$ and continuation utility $J$ that takes the form

$$
f(C, J)=\frac{\beta}{\rho}\left((\alpha(Z) J)^{1-\frac{\rho}{\alpha(Z)}} C^{\rho}-\alpha(Z) J\right),
$$

with $\rho=1-\frac{1}{\psi}$ and $\alpha(Z)=1-\gamma(Z)$, and $\beta>0, \psi>0, \gamma(Z)>0$. Here, $\gamma$ has the standard interpretation of the coefficient of relative risk aversion and is allowed to depend on the aggregate state $Z$. Further, $\beta$ is the rate of time preference, and $\psi$ is the elasticity of intertemporal substitution. Household maximization implies that a statepricing process $\xi_{t}$ may be written as follows.

PROPOSITION 1 (Stochastic discount factor). The stochastic discount factor follows a Markov-modulated jump process,

$$
\frac{d \xi_{t}}{\xi_{t-}}=-r_{f}\left(Z_{t-}\right) d t+\sum_{Z^{\prime} \neq Z_{t-}}\left(e^{\phi\left(Z_{t-}, Z^{\prime}\right)}-1\right)\left(d N_{t}\left(Z_{t-}, Z^{\prime}\right)-\lambda_{Z_{t-} Z^{\prime}} d t\right)
$$

where $r_{f}\left(Z_{t}\right)$ is the real risk-free rate, $N_{t}\left(Z, Z^{\prime}\right)$ is a counting process that keeps track of the number of Markov chain jumps from state $Z$ to state $Z^{\prime}$, and $\phi\left(Z, Z^{\prime}\right)$ is defined as follows:

$$
\phi\left(Z, Z^{\prime}\right) \equiv\left(1-\frac{\rho}{\alpha(Z)}\right) \log \left(\frac{F\left(Z^{\prime}\right)}{F(Z)}\right)
$$

Proof. See Appendix. 


\subsection{The Firm}

Given this paper's focus on asset pricing implications of financial distress, I consider a firm that already has issued debt in the past. Specifically, at time $t=0$, the firm has legacy debt in place that promises debt holders a perpetual coupon rate $c$ normalized to 1.8 Firm-specific Markov states $z$ govern the firm's earnings rates $X(z)$. Let $\lambda_{z, z^{\prime}}(Z)$ denote the transition rate of from firm-state $z$ to $z^{\prime}$ given the economy is in aggregate state $Z$.

Firm-specific Markov states. I consider a stylized Markov chain setup that allows studying the effects of learning on equity values in the presence of aggregate risk while maintaining analytical tractability and transparency. I divide the set of states $(z, Z) \in \Omega$ into four subsets: initial liquid states $\Omega_{l}$, illiquid states $\Omega_{i}$, and two sets of revealing states denoted by $\Omega_{g}$ and $\Omega_{b}$. Initially, the firm is assumed to be in liquid states $(z, Z) \in$ $\Omega_{l}=\left\{l_{g}, l_{b}\right\} \times\{G, B\}$ in which it generates sufficiently high earnings to cover its interest expenses, specifically, $X\left(l_{g}\right)>X\left(l_{b}\right)>c$. From the liquid states $\Omega_{l}$ the firm can transition into illiquid states $(z, Z) \in \Omega_{i}=\left\{i_{g}, i_{b}\right\} \times\{G, B\}$ in which earnings are below the coupon rate $c$, implying that the firm has to raise equity in order not to default. Specifically, the firm's earnings rate is given by $x<c$ in all illiquid states $\Omega_{i}$. A firm that is in the illiquid states may either experience an endogenous default decision by equity holders at some point, or it transitions into states that reveal its true underlying type (insolvent vs. solvent). Let $\Omega_{g}$ and $\Omega_{b}$ denote the two sets of revealing states into which the firm may transition from the firm-states $z=i_{g}$ and $z=i_{b}$ respectively. These revealing states may be thought of as states in which earnings either deteriorate even further so that it is clear that equity holders want to default immediately $\left(\Omega_{b}\right)$, or earnings revert back up above the coupon rate $c$ so that equity holders definitely want to hold on to the firm $\left(\Omega_{g}\right)$. Figure $\mathbb{I}$ illustrates this Markov chain setup.

The decision problem. The decision problem at the heart of the analysis arises in illiquid states, since equity holders have to determine whether the firm is merely illiquid or in fact truly insolvent and should be abandoned. Specifically, the firm-specific states $i_{g}$ and $i_{b}$ are defined so that the firm is solvent in state $i_{g}$ but insolvent in state $i_{b}$. In other words, if investors knew the true state of the illiquid firm, they would choose to default in state $i_{b}$ and inject new funds to cover interest payments in state $i_{g}$. However, since

\footnotetext{
${ }^{8}$ Since taxes are not essential to any of the effects discussed, I abstract from them.
} 
the firm's earnings rate in both these states is given by $x$, investors cannot directly infer the true underlying firm-state $z$ when observing earnings. Yet all investors are Bayesian learners and form rational beliefs about the underlying state based on available information, such as the passage time and other potential signals. If there was no inference

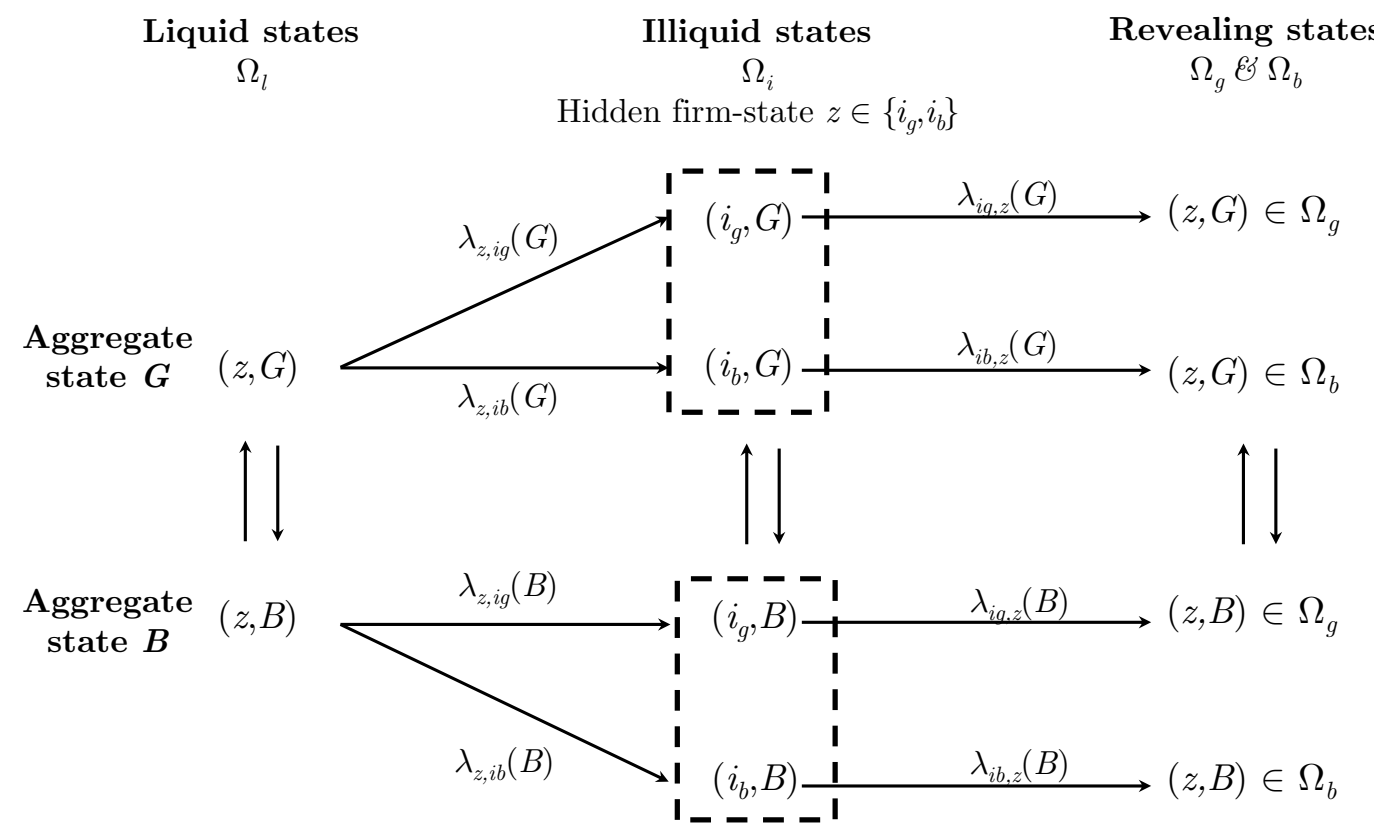

FIGURE I

The figure illustrates the firm's Markov state setup.

problem with regards to the firm-state $z$ and equity holders knew with certainty that the firm was in firm-state $i_{b}$, they would immediately trigger default. On the other hand, if equity holders' knew the firm was in firm-state $i_{g}$, they would be willing to provide new equity to the firm, as the firm is merely illiquid and not insolvent. Naturally, the inference problem becomes degenerate if the equity value in firm-state $i_{g}$ is also not strictly positive, since in that case the illiquid firm is always insolvent.

Alternative Markov state dynamics. To illustrate the effect of learning in the most parsimonious way, the setup deliberately considers the case in which the firm's state is observable up until the point when it obtains a negative shock that causes its earnings to drop below the required coupon payments. This negative shock may either be severe such that the firm will not be able to recover, or more benign, implying that the firm is temporarily illiquid but fundamentally solvent. Equity holders are eager to learn about the underlying new state of the firm in order to make financing or default decisions that 
is in their best interest. More generally, uncertainty about the nature of a shock to firm fundamentals could already arise while a firm is still generating positive dividends. In this case, the shock would not raise an immediate question about the optimality of default, since a firm that generates positive dividends is always currently solvent. However, if the firm were to enter an illiquid state later on, equity holders would again use past firm performance to form beliefs about the nature of the shock (severe vs. benign) and correspondingly firm solvency. More generally, the mechanisms highlighted in this paper merely require that investors face uncertainty about a hidden firm state that can affect current or future firm solvency. The fact that in the considered setup this uncertainty arises exactly when the firm becomes illiquid is not essential but allows illustrating the effects of learning and information acquisition in a simple and parsimonious way.

\subsection{Analysis}

Solving for equity values backwards, I first analyze the revealing states $\Omega_{b}, \Omega_{g}$, then illiquid states $\Omega_{i}$, and finally the initial liquid states $\Omega_{l}$.

\subsubsection{Equity Values in Revealing States}

In the long-run, the firm either has defaulted while being in an illiquid state $\left(\in \Omega_{i}\right)$ or has reached revealing states $\left\{\Omega_{b}, \Omega_{g}\right\}$. I will assume throughout that the firm is truly insolvent in the revealing states $(z, Z) \in \Omega_{b}$, that is, the equity value is zero. The equity values in the good revealing states $(z, Z) \in \Omega_{b}$ are characterized in the following proposition.

PROPOSITION 2 (Equity value in revealing states). In the states $(z, Z) \in \Omega_{g}$, the firm's equity value is given by

$$
V\left(z_{t}, Z_{t}\right)=\max _{\left\{\tau^{*}\right\}} E_{t}\left[\int_{t}^{\tau^{*}} \frac{\xi\left(Z_{\tau}\right)}{\xi\left(Z_{t}\right)}\left(X\left(z_{\tau}\right)-c\right) d \tau\right]=v\left(z_{t}, Z_{t}\right)^{+}
$$

where the function $v(z, Z)$ solves a system of equations that is provided in Appendix B.2.

Proof. See Appendix.

Based on the solution to the household value function provided in the proof to Proposition 1 it is straightforward to compute the equity value according to Proposition 2. Given 
the state-contingent equity values, the risk premium in state $(z, Z)$, denoted by $r p(z, Z)$, may be written as follows:

$$
r p(z, Z)=\sum_{Z^{\prime} \neq Z} \lambda(Z)\left(e^{\phi\left(Z, Z^{\prime}\right)}-1\right)\left(\frac{V\left(z, Z^{\prime}\right)}{V(z, Z)}-1\right), \forall V(z, Z)>0 .
$$

The risk premium is naturally only defined for states $(z, Z)$ in which the firm is still operating and the equity value $V(z, Z)$ is positive.

\subsubsection{Illiquid States $\left(\Omega_{i}\right)$}

Let $V\left(i_{g}, Z_{t}\right)$ denote the equity value of the firm if investors know with certainty that the firm is in state $i_{g}$. I provide a solution to the price $V\left(i_{g}, Z_{t}\right)$ in the appendix. By definition, the equity value in state $i_{b}$ is zero $\left(V\left(i_{b}, Z_{t}\right)=0\right)$, that is, if equity holders knew the firm is in state $i_{b}$ they would opt to default immediately. Yet, generally, when the firm is illiquid and generates earnings at rate $x<c$, investors are uncertain about the underlying firm-state $z \in\left\{i_{b}, i_{g}\right\}$ and therefore may keep the firm afloat even though the underlying state is $i_{b}$. Let $\pi(t)$ denote the probability that the firm is in state $i_{g}$, that is, $\pi(t) \equiv \operatorname{Pr}\left[z=i_{g} \mid \digamma_{t}\right]$. The following proposition characterizes the evolution of posterior beliefs in illiquid states $\Omega_{i}$.

LEMMA 1 (Posterior beliefs in illiquid states). The initial value of the probability that the firm is in state $i_{g}$ at the time of transition into the illiquid state is given by

$$
\pi_{0}=\frac{\lambda_{l, i_{g}}\left(Z_{0}\right)}{\lambda_{l, i_{g}}\left(Z_{0}\right)+\lambda_{l, i_{b}}\left(Z_{0}\right)}
$$

Posterior beliefs $\pi(t)$ evolve as follows:

$$
d \pi_{t}=\varpi(Z)\left(1-\pi_{t}\right) \pi_{t} d t-\pi d N_{t}^{b}+(1-\pi) d N_{t}^{g}
$$

where $\varpi(Z)$ is defined as

$$
\varpi(Z)=\sum_{z^{\prime} \in \Omega_{b}} \lambda_{i_{b}, z^{\prime}}(Z)-\sum_{z^{\prime} \in \Omega_{g}} \lambda_{i_{g}, z^{\prime}}(Z)
$$

and where $N_{t}^{j}$ for $j \in\{g, b\}$ is a counting process that switches from 0 to 1 when the firm jumps into the set of revealing states $\Omega_{j}$ for the first time. Let $\tau_{Z}(t)$ denote the time period for which the firm has been illiquid while in aggregate state $Z$. The posterior 
probability $\pi_{t}$ is given by

$$
\pi(t)=\left(1+e^{\left(-\sum_{\forall Z} \tau_{Z}(t) \cdot \varpi(Z)\right)} \cdot \frac{1-\pi_{0}}{\pi_{0}}\right)^{-1} .
$$

Proof. The results follow from Bayes law.

If $\varpi(Z)$ is constant across aggregate states $Z$, then the inference problem simplifies in the sense that conditional on observing illiquidity $(x<c)$, there is a one-to-one mapping between the posterior probability $\pi$ and the time since the last transition into the illiquid state. Otherwise, the posterior probability also depends on the relative time spent in aggregate states $B$ vs. $G$. Further, if $\varpi(Z)=0, \forall Z$, then passage time alone does not alter beliefs $\pi_{t}$.

The following proposition characterizes the equity value in illiquid states.

PROPOSITION 3 (Equity value in illiquid states). The firm's equity value in illiquid states is given by

$$
V^{R}\left(\pi_{t}, Z_{t}\right)=\max _{\left\{\tau^{*}\right\}} E_{t}\left[\int_{t}^{\tau^{*}} \frac{\xi\left(Z_{\tau}\right)}{\xi\left(Z_{t}\right)}\left(X\left(z_{\tau}\right)-c\right) d \tau\right]=v^{R}\left(\pi_{t}, Z_{t}\right)^{+}
$$

where the function $v^{R}(\pi, Z)$ solves a system of ODEs that is provided in Appendix B.4. Equity holders optimally default in aggregate state $Z$ when posterior beliefs $\pi$ fall below an endogenous cutoff value $\pi^{R}(Z)$ that is determined by the solution of the system.

Proof. See Appendix B.4.

Equity holders optimal default strategy can be summarized by the belief thresholds $\pi^{R}(Z)$ for $Z \in\{G, B\}$. Equity holders keep the firm afloat as long as beliefs are above these state-contingent thresholds. I use the superscript $R$ to indicate that this equity value will constitute a reservation value in section 3, where I discuss the extended model that features an active investor.

\subsubsection{Initial Liquid States $\left(\Omega_{l}\right)$}

Finally, we can characterize the equity values in initial liquid states $\left(\Omega_{l}\right)$.

PROPOSITION 4 (Equity value in initial liquid states). In the initial liquid states 
$(z, Z) \in \Omega_{l}$ the firm's equity value is given by

$$
V\left(z_{t}, Z_{t}\right)=\max _{\left\{\tau^{*}\right\}} E_{t}\left[\int_{t}^{\tau^{*}} \frac{\xi\left(Z_{\tau}\right)}{\xi\left(Z_{t}\right)}\left(\left(X\left(z_{\tau}\right)-c\right) d \tau\right)\right]
$$

where the function $V(z, Z)$ solves a system of equations that is provided in Appendix B.5.

Proof. See Appendix B.4.

\subsection{A Parameterized Illustration}

In this section, I consider solutions to a parametrization of the model that aims to illustrate the effects of learning on equity risk premia when firms are close to default. Table 1 in the Appendix reports chosen parameter values common to all parameterizations in this paper. I consider a parametrization that shows how in such an environment learning can cause negative expected return premia for firms that are close to default, generating striking dynamics in expected returns as the firm approaches the default boundaries.

Figure II plots equity values when the firm is in an illiquid state and the underlying firm-state is hidden. Here, the two state variables determining equity values are beliefs about the firm-specific state, $\pi$, and the observable aggregate state $Z$. In the left-hand side panel, equity values are plotted over a wider region of beliefs. The right-hand side panel of Figure II zooms in and provides a more detailed view of equity values close to the default boundary. Whereas the equity value in the good aggregate state $G$ is higher than the one in the bad state $B$ for higher values of $\pi$, the opposite is true in a region close

to default. Here the equity value in the bad aggregate state is higher, implying negative co-movement of equity values with aggregate conditions at a business cycle frequency.

In the parametrization, earnings fundamentals are strongly positively correlated with aggregate growth (see caption of Figure II): a solvent firm $\left(i_{g}\right)$ is significantly more likely to transition back into a state with higher earnings when the aggregate economy is in a good state $(G)$ than when it is in a bad state $(B)$. Similarly, a truly insolvent firm $\left(i_{b}\right)$ is more likely to exhibit further deteriorating earnings when the aggregate economy is in a downturn $(B)$ than when it is in a boom $(G)$. The chosen pro-cyclical parameterization of earnings dynamics implies the intuitive notion that illiquid firms that show resilience in downturns $(B)$ by maintaining stable earnings see upward revisions in posterior beliefs over time. In other words, passage time in the illiquid state in a downturn $(B)$ increases investors' posterior beliefs about the hidden firm state and correspondingly lead to an 
Equity Value

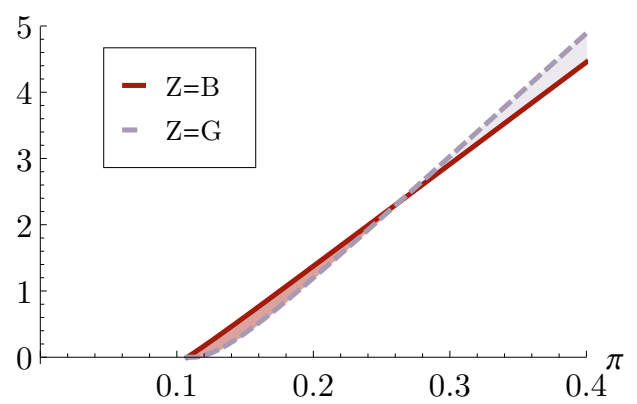

Equity Value Close To Default

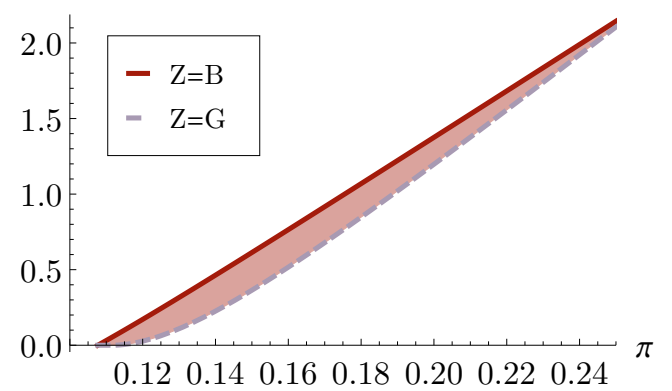

FIGURE II

The graphs plot the equity value of the firm as a function of investors' beliefs about the firm's hidden state. The graph in the left-hand side panel plots the equity value over a range of beliefs $\pi \in[0,0.4]$. The right-hand side panel provides an enlarged picture of the equity value for beliefs $\pi$ close to the default boundaries. Given the firm's true state is $i_{g}$ (solvent), earnings revert back up above the coupon rate with a total hazard rate $\left(\sum_{\Omega_{g}} \lambda_{i_{g}, z}(Z)\right)$ of 0.25 and 0.40 in aggregate states $B$ and $G$ respectively. Given the firm's true state is $i_{b}$ (insolvent), earnings deteriorate further and reveal insolvency with a total hazard rate $\left(\sum_{\Omega_{b}} \lambda_{i_{b}, z}(Z)\right)$ of 0.65 and 0.25 in aggregate states $B$ and $G$ respectively. All other parameters are provided in Table 1 in Appendix A.

increase in equity values $!^{9}$ In contrast, in booms, stable earnings are considered a bad signal, since truly solvent firms are likely to show improvements in earnings performance in the face of good overall economic conditions $(G)$. Passage time in the illiquid state in booms is thus seen as a sign of weakness and associated with decreasing beliefs and declining equity values. In terms of the graphs in Figure II, in bad times $(B)$, firms that do not receive news about earnings changes drift upwards on their equity value function. In contrast, in good times $(G)$, the equity value drifts downwards absent news and smoothly approaches a value of zero, where equity holders trigger default.

Expected returns and momentum. The negative comovement between aggregate conditions and firm equity values in a region of beliefs $\pi_{t}$ close to the default boundaries imply negative equity risk premia. Figure III illustrates expected equity returns as functions of beliefs $\pi$ (left-hand side graphs) and passage time without events (right-hand side graphs). Negative news about the firm leads to a downward revision in beliefs $\pi$ and a negative contemporaneous return ("recent loser"). Interestingly, since the firm is closer to the default boundary after such a negative news shock, it also has lower expected

\footnotetext{
${ }^{9}$ Statements about the evolution of beliefs as a function of passage time condition on the realization of no jumps. Unconditionally, beliefs about the hidden firm state are naturally martingales.
} 
Equity Risk Premia And Beliefs

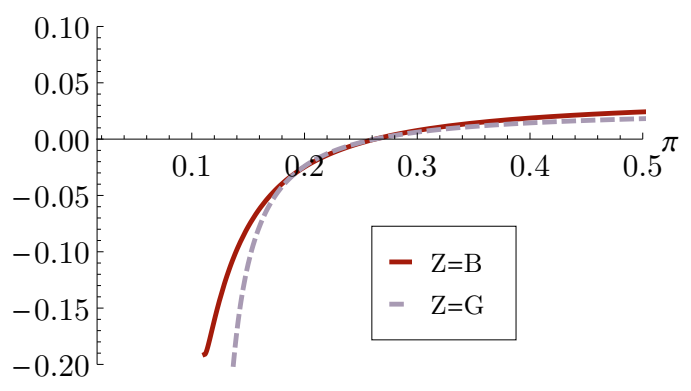

Equity Risk Premia And Passage Time

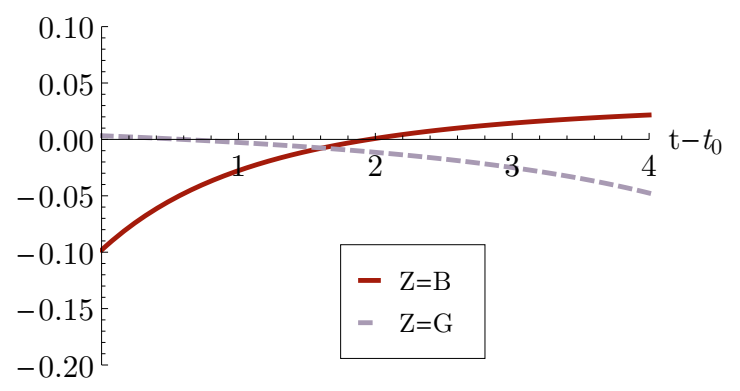

FIGURE III

The figure illustrates equity risk premia as a function of beliefs $\pi$ (left-hand side) and passage time absent events such as changes in the earnings rate (right-hand side). In the graph on the right-hand side, starting values for beliefs $\pi$ are 0.5 and 0.15 in aggregate states $G$ and $B$ respectively. The graphs are based on the same parameterization as Figure II.

equity returns going forward 10 Conversely, good news that is associated with positive price changes ("recent winners"), pushes the firm away from the default boundary and implies higher expected equity returns going forward. A momentum strategy that goes long recent winners and shorts recent losers may therefore generate a large spread in expected returns. While the model reconciles these positive correlations between recent price changes and expected returns for financially distressed firms, it predicts that the phenomenon goes away the larger a firm's distance is from default. This result is consistent with the empirical finding of Avramov, Chordia, Jostova, and Philipov (2007) that both the long and the short portfolio of momentum strategies consist of stocks with high default risk. According to the model, distressed firms are good candidates for portfolio strategies that sort on past returns, since their past returns are strongly correlated with changes in expected returns going forward.

The benefits of recessions. The illustration highlights effects that are related to the notion that recessions have a "cleansing effect" on the economy (Schumpeter, 1934). When faced with the test of a downturn, truly insolvent firms are more likely to quickly exhibit further deteriorating earnings, making it clear to equity holders that further equity injections are not worthwhile and default is optimal. Empirically, this is consistent with waves of defaults that typically occur in recessions and that motivated Schumpeter's

\footnotetext{
${ }^{10}$ More generally, one could extend the model to incorporate the arrival of new signals that lead to an updating of beliefs independent of contemporaneous earnings changes.
} 
theory ${ }^{11}$ Given that under current beliefs $\pi_{t}$, the equity value is positive and equity holders currently inject more funds, it is valuable to them if the firm, given it is in state $i_{b}$, will quickly show such adverse performance that they can easily conclude that default is optimal - in other words, it is valuable if equity holders' beliefs converge quickly toward the truth in the future, especially conditional on the truth being bad. A fast expected revelation of truly insolvent firms increases the equity value, as it limits expected future losses equity holders will make by mistakenly injecting funds into truly insolvent firms. Given the "test of a downturn", truly insolvent firms $\left(i_{b}\right)$ are less likely to be able to maintain stable earnings and pool with good firms $\left(i_{g}\right)$, which improves the quality of information equity holders use to make default decisions. Since the default option is a key determinant of the equity value when the firm is close to default, learning can even induce negative co-movement between distressed firms' equity values and aggregate conditions at a business-cycle frequency. In fact, everything else equal, an increased hazard rate of adverse performance by insolvent firms in downturns, which increases the pro-cyclicality of earnings fundamentals, decreases equity risk premia.

In section 3, I extend the presented baseline model to account for endogenous information acquisition by active investors. In this context, I will show that if learning about insolvent firms based on earning performance is not fast in downturns, active investors have a natural incentive to acquire information in these times and supplement exogenous signals about firm solvency with endogenous signals.

\subsection{Empirical Implications}

When relating the predictions of the model to the empirical literature it is important to note that empirical papers study expected returns of financially distressed stocks at the portfolio level. Studies such as Campbell, Hilscher, and Szilagyi (2008) sort the cross-section of stocks based on default likelihood measures and then form portfolios using quintile or decile breakpoints. The degree to which firms in these portfolios are financially distressed varies therefore naturally over the business cycle. In particular, the average firm in the quintile of most distressed stocks is generally more financially distressed during a recession than during a boom. This is due to the empirical fact that

\footnotetext{
${ }^{11}$ Despite the similarities, there are some important differences between the objects that Schumpeter addressed and the ones that I am addressing in this paper. In this paper, I focus on equity values, whereas Schumpeter was concerned with overall economic value of abandoning unworthy projects in downturns. To the extent that insolvency is not just a result of excessive leverage but also a sign of a firm's general lack of economic viability, the described benefits of learning are however related to Schumpeter's ideas.
} 
leverage tends to increase after a series of bad shocks, since firms do not instantaneously adjust their capital structure. Given the model's prediction that firms that are closer to default have lower exposures to business-cycle frequency risks, this implies that the quintile of most distressed stocks will have lower betas with respect to these risks in downturns. Since market risk premia tend to be high in recessions, the model thus can rationalize a negative correlation between market risk premia and portfolio betas. This negative correlation however leads to the problem that unconditional CAPM regressions yield positively biased betas and negatively biased alphas 12 Consistent with this prediction, O'Doherty (2012) finds empirically that the conditional betas of the quintile of stocks that are most distressed are lower in downturns and are negatively correlated with measures of the market risk premium. O'Doherty $(2012)$ further estimates that this negative correlation can account for roughly two thirds of the unconditional alpha of financially distressed firms in US data. O'Doherty]s (2012) estimation approach which follows Boguth, Carlson, Fisher, and Simutin (2011) does however use relatively high frequency data which is a necessary evil given the limited time period for which data that is available. Yet according to the theory proposed in this paper, one would ideally explicitly estimate time-varying low-frequency risk exposures. Estimating these low-frequency risk exposures precisely would however require larger amounts of data.

\section{The Extended Model with Private Placements}

In this section, I present an extended model featuring an active investor that can produce information on the firm's underlying hidden state. After analyzing this extended model and illustrating the main findings, I provide further discussions of the robustness of the model's predictions with respect to alternative specifications of the active investor's technology and the Markov state dynamics (see subsection 3.4.

\subsection{The Active Investor}

An active investor is endowed with an information production technology that allows acquiring costly information on the firm's true underlying state. When the firm is in an illiquid state $(z, Z) \in \Omega_{i}$, the technology generate a perfectly precise signal of the hidden firm state $\left(z \in\left\{i_{b}, i_{g}\right\}\right)$ with a Poisson arrival rate $a_{t}^{1-\eta}$, where $a_{t}$ denotes effort exerted

\footnotetext{
${ }^{12}$ See, e.g., Grant (1977) and Jagannathan and Wang (1996).
} 
by the active investor and $\eta \in(0,1)$. The active investor incurs cost at rate $a_{t} \chi$ (with $\chi>0$ ) for exerting effort $a_{t}$. Effort is not directly observable and not contractible.

Contracting. The analysis considers contracts between management and the active investor that provide the active investor with new equity shares that yield an ownership share $\omega$ at a purchase price $\bar{\kappa}$. Management acts in the interest of existing shareholders. Contracts are limited to one-time provisions of new equity at a price that dilutes existing shareholders. Management does not renegotiate the contract in the future so that any future equity injections by the active investor occur at the same terms as for all other investors. In principle, the contract may be written at any point in time $\bar{t}>0$. Yet there is no reason to provide the active investor with an equity exposure before the firm enters the illiquid states $\Omega_{i}$, since the active investor's information technology is only useful in states in which the underlying firm-state $z$ is unknown.

The active investor's equity exposure. The active investor faces limits to the amount of capital it can allocate to the firm, implying an upper bound on the feasible equity share allocated to the active investor. The upper bound on $\omega$ may be due to capital constraints or cost of un-diversification that limit the optimal amount of exposure for the active investor. Since this paper does not attempt to provide an explanation for various economic forces that may limit the investor's exposure, I consider the upper bound on $\omega$ as exogenously given and focus on the asset pricing implications for a given upper bound.

Information environment. Adjustments to the active investor's position in the firm are assumed to be publicly observable. The lack of noise in the system implies that the active investor will not be able to extract rents from trading against less informed investors, since market participants understand that the investor's only motive for trade is information. The paper thus focuses on active investors' ability to make profits by affecting firm policies rather than by trading against less informed parties. This view is consistent with the general notion that active investors, after obtaining a stake in a company, are actually involved in evaluating and shaping firm policies going forward. There are several other reasons why I take this route.

First, in the case of private investments in public equity ("PIPEs"), which are a typical form of investments by active investors in distressed equity, management is directly involved in the transaction and has the fiduciary duty to act in the interest of existing 
shareholders. In these transactions, management typically deliberately offers profits to active investors by providing them with securities at discounted prices (see, e.g., Park (2013)). This source of gains for active investors is exactly captured in my model.

Second, regulation in the United States requires that investors acquiring more than $5 \%$ of a firm's equity with the intent to exert control have to file a $13 \mathrm{~d}$ with the SEC within 10 days. In addition, investors have to re-file these forms in case of material changes to their positions (1\%). These required regulatory filings ensure that information about an active investor's exposure becomes public at a high-enough frequency to help inform other equity holders' future financing and default decisions, which is the central externality channel highlighted in this extended model.

Third, whereas adding noise to the system (for example by introducing noise traders or liquidity shocks) would be an interesting extension in its own right, it would be somewhat distracting in the context of this paper which aims to address empirical facts on existing shareholders' buy-and-hold returns after private investments in public equity. A buy-and-hold strategy does not correspond to random or selective buy-and-sell orders that are typical equilibrium outcomes of noisy rational expectations models. Low buy-and-hold returns for existing shareholders cannot be explained by losses from trades against informed counterparties. Further, adding noise to the system comes at the cost of reducing analytical tractability and transparency.

Usage of excess cash. New funds provided by the active investor are invested in marketable securities until the funds are used to either make contractual coupon payments to debt holders, or until management strategically liquidates the firm. In case of strategic liquidation, management sells the marketable securities and pays out the proceeds as a dividend to equity holders. Further, if the firm runs out of excess cash before its earnings have recovered or a default has occurred, new equity may be raised to make coupon payments (just as in the baseline model) ${ }^{13}$

Bargaining power. Management acting in the interest of existing equity holders naturally has the outside option not to issue shares to the active investor. The value of the

\footnotetext{
${ }^{13}$ The assumption that excess cash can be paid out as a dividend at any time simplifies the analysis, as it implies that excess cash is not a state variable that affects default decisions. This assumption is however not essential for the highlighted qualitative results. If management could not pay out excess cash, then equity holders would never choose to default while the firm still has a strictly positive excess cash position. However, once the firm has used up its excess cash to make coupon payments, the same optimal default strategy applies as in the setup discussed here.
} 
equity under this scenario constitutes the reservation value, $V^{R}$, that implies a limit on the price discount management is willing to offer the active investor for shares in the

firm. For simplicity, I consider the case where the active investor has all the bargaining power when the contract is written, allowing it to obtain a purchase price that leaves old shareholders just indifferent between the private placement of shares and the alternative situation in which the active investor does not obtain a stake in the firm. All results are qualitatively robust to cases in which the active investor cannot extract all the rents it generates for equity holders by acquiring information. For the results on expected return dynamics it is only essential that the active investor obtains a stake in the firm that provides incentives to exert effort to acquire information on firm fundamentals. The distribution of bargaining power only alters the degree of initial dilution of existing shareholders. Empirically documented dilution of existing shareholders via private placements of public equity suggests that active investors are in fact able to extract part of the rents they generate (see, e.g., Park (2013)).

\subsection{Analysis}

\subsubsection{Illiquid States $\left(\Omega_{i}\right)$}

The active investor's information production technology can generate rents for equity holders when the firm is in illiquid states and there is uncertainty about the firm's solvency. Providing the active investor with an equity stake thus optimally occurs as soon as the firm enters an illiquid state and generates earnings at rate $x<c$. Note that there is no uncertainty about the firm's state until it transitions into the illiquid state, implying that there is no room for learning or information production in the initial liquid states $\Omega_{l}$. As discussed in Lemma 1, investors' conditional beliefs at that time when the firm transitions into an illiquid state are given by $\pi_{0}(Z)$, implying that the reservation value is given by $V^{R}\left(\pi_{0}\left(Z_{t}\right), Z_{t}\right)$.

Let $V(\pi, Z, \bar{\kappa})$ denote the total equity value at the time when the active investor acquires a stake in the firm at price $\bar{\kappa}$. The issuance of new equity to the active investor implies a cash infusion, generating an initial excess cash position of $\bar{\kappa}$ for the firm. While in the illiquid state, the firm's excess cash balance evolves according to

$$
d \kappa=(x-c) d t
$$

as long as the firm still has cash $\kappa_{t}>0$ and is not liquidated. The following proposition 
characterizes the solution to the active investor's dynamic decision problem conditional on holding an $\omega$-share of the equity in the firm.

PROPOSITION 5 (Value of the active investor in illiquid states). In the illiquid state, the active investor's value is given by

$$
\begin{aligned}
V^{A}\left(\pi_{t}, Z_{t}, \kappa_{t}\right) & =\max _{\left\{\tau^{*}, a\right\}} E_{t}\left[\int_{t}^{\tau^{*}} \frac{\xi\left(Z_{\tau}\right)}{\xi\left(Z_{t}\right)}\left(\omega\left(X\left(z_{\tau}\right)-c\right)-a_{t} \chi\right) d \tau+\frac{\xi\left(Z_{\tau^{*}}\right)}{\xi\left(Z_{t}\right)} \omega \kappa_{\tau^{*}}\right] \\
& =v^{A}\left(\pi_{t}, Z_{t}\right)^{+}+\omega \kappa_{t} .
\end{aligned}
$$

The function $v^{A}(\pi, Z)$ solves a system of ODEs that is provided in Appendix B.6. The active investor optimally proposes default whenever she obtains a bad signal, or when in aggregate state $Z$ posterior beliefs $\pi$ fall below an endogenous cutoff value $\pi^{A}(Z)$ that is determined by the solution of the system. The active investor's optimal information acquisition effort is given by

$$
\left.a(\pi, Z)=\left(\frac{\eta(1-v)}{\chi}\left(\pi \omega V\left(i_{g}, Z\right)-v^{A}(\pi, Z)\right)\right)\right)^{\frac{1}{v}}, \text { for } \pi>\pi^{A}(Z)
$$

Proof. See Appendix B.6.

The active investor optimally proposes the payout of cash (if $\kappa_{t}>0$ ) or simply abandons the firm (if $\kappa_{t}=0$ ) when the discounted present value of its opportunity cost of information production and net-dividends falls below zero. This solution again corresponds to a cutoff strategy in the posterior belief $\pi$ that depends on the aggregate state $Z$. Specifically, if the conditional probability that the firm is solvent, $\pi_{t}$, drops below a threshold $\pi^{A}\left(Z_{t}\right)$, the active investor proposes liquidation or abandons the firm. For $\pi_{t}>\pi^{A}\left(Z_{t}\right)$, it is incentive compatible for the active investor to hold on to the equity share $\omega$ and to utilize the information production technology to the extent that it maximizes the active investor's value.

Proposition 5 characterizes the active investor's optimal behavior conditional on a given $\omega$-share in the firm. The optimal share $\omega$ is given by the maximum feasible $\omega \in[0,1]$ subject to the active investor's capital constraint. Absent capital constraints or other forces that limit the active investor's exposure to the firm (such as cost of undiversification), the active investor optimally obtains a $100 \%$ stake in the firm such that it fully internalizes equity holders' benefits from employing its information production technology. With a 100\% stake the active investor maximizes total rents to equity holders and equalizes equity holders' marginal gains from improved information quality with 
marginal information production cost.

If the active investor obtains a bad signal $s=i_{b}$, she will propose a dividend payment if the firm currently has excess cash $\left(\kappa_{t}>0\right)$ and refuse further equity injections. Attempting to sell the equity stake will yield a price of zero, since other investors can infer that the active investor must have received a negative signal if current beliefs $\pi_{t}$ are above the threshold $\pi^{A}\left(Z_{t}\right)$. Since a signal $s=i_{b}$ implies that the firm is insolvent, other equity holders will support the active investor's proposal to pay a dividend and will also abandon the firm thereafter. Through this channel, equity holders may effectively free ride on the active investor's information production once the active investor is exposed to the firm's equity. The following proposition characterizes the value of the equity in the presence of this externality.

PROPOSITION 6 (Equity value in illiquid states with active investor). The firm's equity value in illiquid states is given by

$$
\begin{aligned}
V\left(\pi_{t}, Z_{t}, \kappa_{t}\right) & =\max _{\left\{\tau^{*}\right\}} E_{t}\left[\int_{t}^{\tau^{*}} \frac{\xi\left(Z_{\tau}\right)}{\xi\left(Z_{t}\right)}\left(\left(X\left(z_{\tau}\right)-c\right) d \tau\right)+\frac{\xi\left(Z_{\tau^{*}}\right)}{\xi\left(Z_{t}\right)} \kappa_{\tau^{*}}\right] \\
& =v\left(\pi_{t}, Z_{t}\right)^{+}+\kappa_{t} .
\end{aligned}
$$

The function $v(\pi, Z)$ solves a system of ODEs that is provided in Appendix B.7. Equity holders optimally agree to default or liquidate the firm when the active investor proposes to do so. Equity holders further choose to default when in aggregate state $Z$ posterior beliefs $\pi$ fall below the endogenous cutoff value $\pi^{A}(Z)$ from the active investor's problem.

\section{Proof. See Appendix B.7.}

Proposition 6 shows that existing shareholders abandon the firm at the same threshold as the active investor, that is at $\pi^{A}(Z)$. The intuition for this result is as follows. The active investor's value is naturally bounded from below by the value of its equity position under a passive strategy, that is $V^{A}(\pi, Z) \geq \omega V^{R}(\pi, Z)$. This is the case since the active investor could always choose to set its effort to zero $\left(a_{t}=0\right)$ and simply hold the equity stake. Since $V^{A}$ and $V^{R}$ are both increasing functions of the probability that the firm is in the solvent state, $\pi(t)$, the active investor's optimal abandonment cutoff $\pi^{A}(Z)$ is always weakly lower than the optimal reservation value cutoff, that is, $\pi^{A}(Z) \leq \pi^{R}(Z)$. Further, as soon as the active investor abandons the firm, other equity holders may no longer free-ride on the active investor's information production, implying that their value is simply captured by $(1-\omega) V^{R}$. The equity value absent

active investor involvement, $V^{R}$, has to be equal to be zero at $\pi(t)=\pi^{A}(Z)$ since the 
active investor value $V^{A}(\pi, Z)$ is zero, and $V^{A} \geq \omega V^{R}$. On the other hand, for beliefs above the abandonment threshold, $\pi(t)>\pi^{A}(Z)$, passive shareholders' equity value must be positive since the active investor's value is positive and passive equity holders benefit from free-riding on the fund's information production, that is, they share the same benefits but do not incur information production cost 14

Excess Cash $\kappa$. Proposition 6 shows that the equity value is additively separable in the excess cash position $\kappa_{t}$ and the equity value corresponding to core assets $v\left(\pi_{t}, Z_{t}\right)^{+}$. The value function simplifies in this way since excess cash may be paid out at any point in time and investments in marketable securities have a zero NPV. Thus, the abandonment decision is independent of the current level of excess cash $\kappa$.

If the active investor has all the bargaining power, existing shareholders obtain exactly their reservation value $V^{R}$ as a result of the equity issuance to the active investor, that is, the purchase price $\bar{\kappa}$ is set such that existing shareholders' stake is worth $V^{R}$ after the equity issuance. For an $\omega$-share in the firm's post-issuance equity the active investor's purchase price is thus given by

$$
\bar{\kappa}=\frac{V^{R}(\pi, Z)}{(1-\omega)}-v(\pi, Z)^{+} .
$$

Existing shareholders' ability to free ride on the information produced by the active investor in the illiquid states therefore does not increase shareholder value in the liquid state given that the active investor has all the bargaining power when it purchases the equity stake.

The value of information in financial distress. Information production by the active investor would not be an equilibrium feature if the firm had no debt, since information would not alter decisions and therefore generate no value.15 The proximity to default makes information valuable to equity holders, and is therefore an integral part

\footnotetext{
${ }^{14}$ As described in the setup, management commits not to renegotiate once the initial contract is written. If renegotiation is allowed, changes to the debt contract could be considered as well, which is outside of the scope of this paper (see, e.g., Garlappi, Shu, and Yan (2008) for analysis of the effects of renegotiation upon default).

${ }^{15}$ In the setup the firm's assets always generate positive dividends, implying that the firm should never be shut down - the abandonment option problem would be trivial. Yet if $c$ is interpreted as a maintenance flow cost required to preserve the assets (instead of a coupon payment) even an all-equity firm benefits from information production. In other words, operating leverage would be an alternative interpretation for the setup.
} 
of the proposed mechanism that jointly drives active investor activity, diluted equity issuances, and dynamics in expected returns. If the active investor were to learn about the firm state, but there was no state of the world in which default was optimal, the decision value of information would be zero and the information production technology would not be used. This is true despite the fact that the setup features stochastic differential utility: there are no gains to acquiring information on the firm-specific state based on an earlyresolution-of-uncertainty motive, since this information does not alter the representative household's information set with regards to aggregate consumption dynamics.

When a firm is in distress, the value of the abandonment option embedded in the equity stake naturally constitutes a particularly large fraction of the total equity value. The option value in turn depends critically on the quality information available to agents that exercise the option. The more precise the information the better are exercising decisions, and the more valuable is the option to the agent. The quality of information is therefore an important determinant of the equity value close to the default boundary. Further, as will be illustrated in the next section, variation in the quality of information therefore also critically affects the co-movement of the firm's equity value with aggregate conditions.

Alternative governance channels. Alternative channels through which active investors may affect firm value include proxy fights, shareholder proposals to replace management, and the alike. Whereas these alternative types of investor activism could be beneficial whenever the firm faces operating decisions, they do not necessarily relate to firms in financial distress: even in the case of an all-equity firm investor activism of this type could affect the firm's decisions and thereby alter exposures to aggregate risk - in other words, proximity to default would not be an essential ingredient. Yet this paper aims to provide a coherent explanation for the fact that the puzzling empirical regularities addressed are all concentrated among firms with high default risk.

\subsection{A Parameterized Illustration}

In this section, I discuss a parametrization that illustrates how endogenous information acquisition by an active investor affects equity risk premia of financially distressed firms. Throughout, I will focus the discussion on the part of the equity value that corresponds to the firm's core assets. The effect of the excess cash position $\kappa$ on the firm's equity risk premium depends on the types of securities the firm invests in, a choice which 
is not uniquely pinned down by the model. Investment in any fairly priced security in the economy would be consistent with shareholder value maximization. To determine the overall risk premium on equity, one simply has to take the value-weighted average of the risk premium on the firm's core assets and the one on its marketable securities.

In the parametrization used for figures II and III, learning from past earnings was strong enough in the bad aggregate state $B$, relative to the good aggregate state $G$ to induce negative equity risk premia close to default. Relative to this parametrization, the following example, illustrated in Figure IV] only changes the values of two transition rates (see caption of Figure IV for details). These different transition rates imply that solvent firms are now much more likely to leave the illiquid state in booms $(G)$, generating larger benefits from learning in these times than in state $B$. Given learning is now strongly procyclical, it does little to counteract the underlying pro-cylicality of earnings dynamics and cannot reverse the standard result that equity risk premia increase as the firm approaches the default boundary.

However, the example reveals that a private placement of a $20 \%$ public equity stake to an active investor can significantly reduce equity holders' expected returns. Figure IV plots the firm's equity risk premium with and without active investor participation in state $G$ (left-hand side) and state $B$ (right-hand side) as a function of beliefs. Further, the figure plots the expected returns on the active investor's position, which includes the active investor's information acquisition cost. The graphs reveal that the participation of an active investor greatly reduces equity risk premia of other equity holders and extends the range of beliefs for which equity holders are willing to keep the firm afloat. Due to the presence of the active investor and its information acquisition, equity holders' option value is increased. The active investor has a higher exposure to aggregate risk than other shareholders, since it endogenously incurs higher information acquisition cost in the bad aggregate state $Z=B$. This implies higher expected returns for the active investor's strategy than for other equity holders.

The example illustrates the stark difference in the dynamics of risk premia with and without the participation of an active investor. This result is directly supported by the empirical finding by Park (2013) that low returns for distressed firms are concentrated among those firms that issue public equity in private placements. The theoretical results of the model in fact also predict that the degree of dilution of existing shareholders is determined by the effectiveness of the active investor and therefore should be negatively related to expected returns going forward. 
Risk Premia in State $\mathrm{Z}=\mathrm{G}$

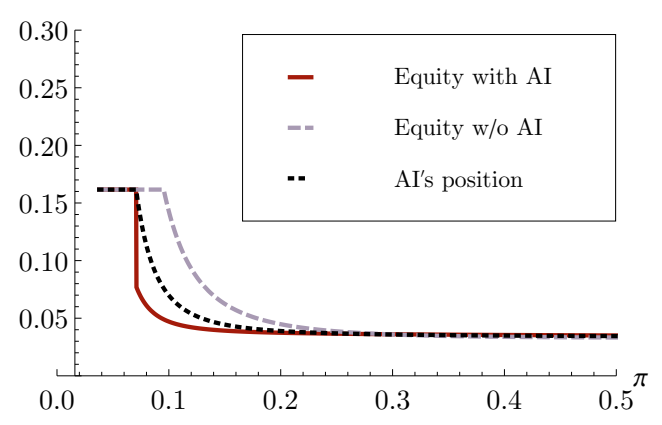

Risk Premia in State $\mathrm{Z}=\mathrm{B}$

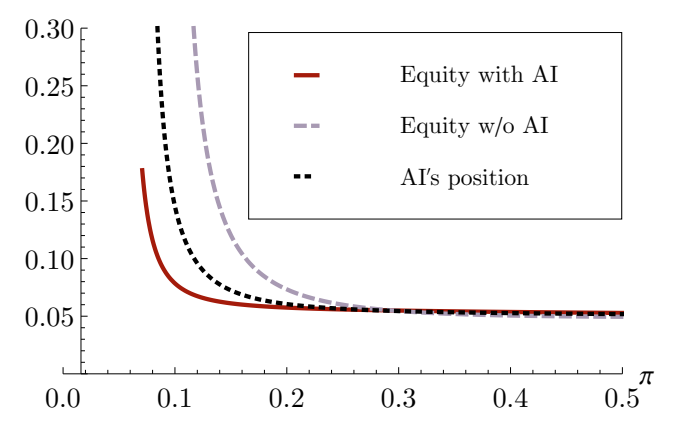

FIGURE IV

The figure plots risk premia for passive equity investors with and without participation of an active investor ("with AI", "w/o AI") and for the active investor ("AI's position") in aggregate states $G$ (left-hand side panel) and $B$ (right-hand side panel). Given the firm's true state is $i_{g}$, earnings revert back up above the coupon rate with a hazard rate of 0.25 and 1.20 in aggregate states $B$ and $G$ respectively. Given the firm's true state is $i_{b}$, earnings deteriorate further and reveal insolvency with a total hazard rate of 0.60 and 0.25 in aggregate states $B$ and $G$ respectively. All other parameters are provided in Table 1 in Appendix A,

\subsection{Robustness}

Endogenous vs. exogenous information. The active investor's participation can also reduce equity risk exposures if the active investor cannot adjust its effort $a_{t}$ over the business cycle. Specifically, the effect of the active investor's participation is still present if the investor is endowed with a constant hazard rate of obtaining a signal on the hidden firm state. I consider endogenous effort to highlight that the active investor would in fact have incentives to acquire information in a way that reduces expected equity returns going forward. Further, it appears reasonable that active investors can at least to some degree choose the extent to which they focus on distressed companies over the business cycle, implying endogenous variation in effort targeted at evaluating distressed firms.

\section{Alternative Markov state dynamics \& precautionary information acquisition.}

As already discussed in section 2.2, it is not essential that uncertainty about the underlying firm state arises only in illiquid states. The Markov chain setup could be extended to capture the notion that investors already face uncertainty about the firm's true state before the firm lacks sufficient funds to make its debt payments. In this case, it would be useful to involve the active investor as soon as this uncertainty arises, even if equity 
holders do not face an immediate default decision at that point in time ${ }^{16}$ This is the case, since it is less costly for the active investor to spread out information acquisition effort over time - in other words, there would be precautionary information acquisition. In addition, precautionary information acquisition would naturally intensify the closer the firm gets to an illiquid state in which the information is actually used to make a well-informed default decision.

\section{Conclusion}

This paper provides a tractable dynamic asset pricing model to analyze the effects of learning and active investors' information production on expected return dynamics of financially distressed firms. The model reveals that learning can rationalize low and even negative expected equity returns for illiquid firms, and that issuances of privately placed public equity to active investors may constitute an important factor influencing expected returns on passive equity holders' positions. Further, the model can explain the empirical finding by Avramov, Chordia, Jostova, and Philipov (2007) that momentum profits are restricted to high credit risk firms and are nonexistent for firms of high credit quality. The analysis suggests that information acquisition by specialized intermediaries may generate substantial externalities on other shareholders and may be related to intriguing empirical facts related to distressed firms' expected returns.

\footnotetext{
${ }^{16}$ As long as the firm generates positive dividends it is always optimal not to default, independent of the underlying hidden firm state.
} 


\section{A. Tables}

Table 1

The table lists common parameter values underlying the illustrations in Figures II, III, and IV.

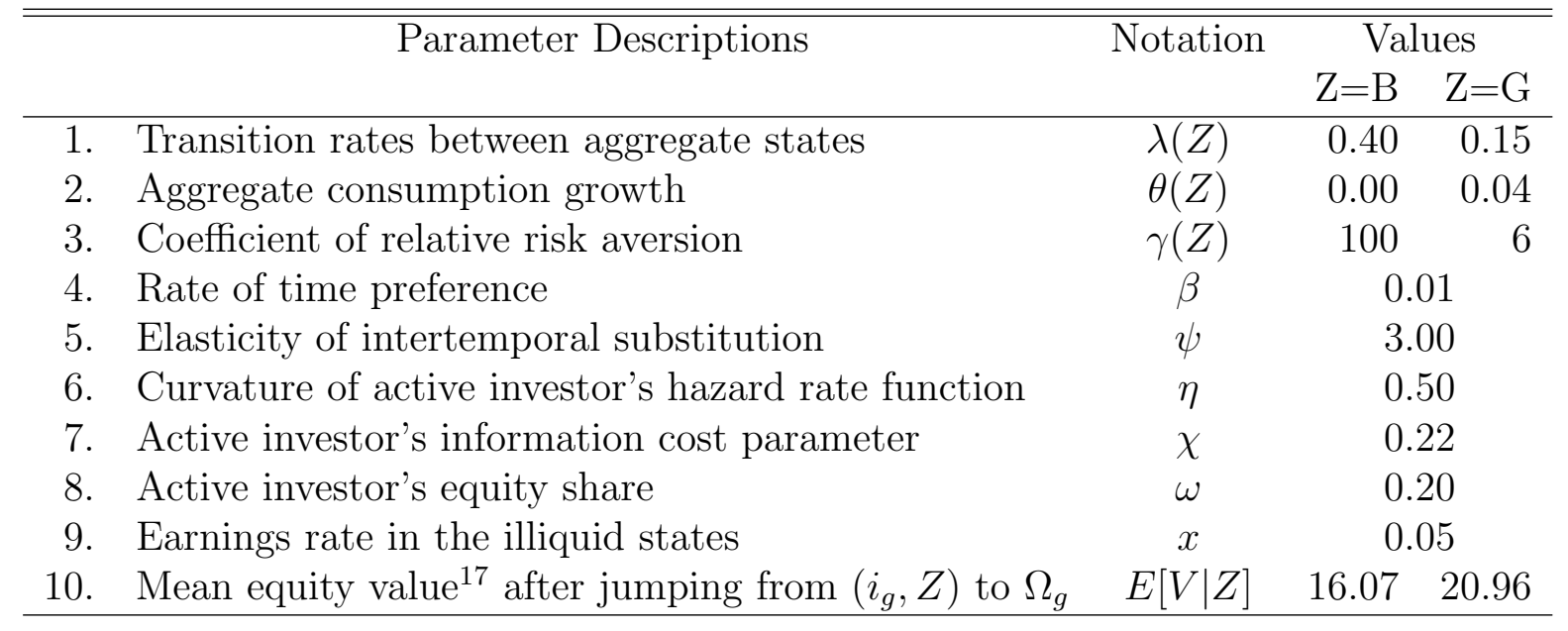

Table 2

The table lists equilibrium values corresponding to the illustrations in Figures II] III. and [V] The term "levered consumption claim" refers to a levered version of aggregate consumption as considered in Abel (1999), using a leverage parameter of 3.5 .

\begin{tabular}{llccc}
\hline \hline & \multicolumn{2}{c}{ Variable Descriptions } & Notation & \multicolumn{2}{c}{ Values } \\
& & $\mathrm{Z}=\mathrm{B}$ & $\mathrm{Z}=\mathrm{G}$ \\
\hline 1. & Risk-free rate & $r_{f}(Z)$ & 0.010 & 0.016 \\
2. & Risk premium of consumption claim & $r p_{C}(Z)$ & 0.013 & 0.010 \\
3. Risk premium of levered consumption claim & $r p_{L}(Z)$ & 0.067 & 0.042 \\
\hline
\end{tabular}




\section{B. Proofs}

\section{B.1. Proof of Proposition 1}

In equilibrium, the representative household consumes the aggregate consumption flow $C_{t}$. The value function is given by

$$
J\left(C_{t}, Z_{t}\right)=E_{t}\left[\int_{t}^{\infty} f\left(C_{\tau}, J_{\tau}\right) d \tau\right]
$$

The Hamilton-Jacoby-Bellman (HJB) equation in state $Z$ (for all $Z \in \Omega$ ) is therefore

$$
0=f(Y, J(Y, Z))+J_{Y}(Y, Z) Y \theta(Z)+\sum_{Z^{\prime} \neq Z} \lambda_{Z Z^{\prime}}\left(J\left(Y, Z^{\prime}\right)-J(Y, Z)\right)
$$

Conjecture the solution for $J$ takes the standard form

$$
J(C, Z)=F(Z) \frac{C^{\alpha(Z)}}{\alpha(Z)}
$$

Substituting this conjecture into the HJB equation yields the following system of nonlinear equations for $F(Z)$, for all $Z$ :

$$
0=\left(\frac{\beta \alpha(Z)}{\rho(Z)}\left(F(Z)^{-\frac{\rho(Z)}{\alpha(Z)}}-1\right)+\alpha(Z) \theta(Z)\right) F(Z)+\sum_{Z^{\prime} \neq Z} \lambda(Z)\left(F\left(Z^{\prime}\right)-F(Z)\right) .
$$

Household maximization implies that a state-pricing process $\xi_{t}$ may be written as follows:

$$
\xi_{t} \equiv \exp \left[\int_{0}^{t} f_{J}\left(C_{\tau}, J_{\tau}\right) d \tau\right] f_{C}\left(C_{t}, J_{t}\right)
$$

Using the value function $J\left(C_{t}, Z_{t}\right)=F\left(Z_{t}\right) \frac{C_{t}^{\alpha\left(Z_{t}\right)}}{\alpha\left(Z_{t}\right)}$ we obtain

$$
\xi_{t}=C_{t}^{\alpha\left(Z_{t}\right)-1} \beta F\left(Z_{t}\right)^{1-\frac{\rho\left(Z_{t}\right)}{\alpha\left(Z_{t}\right)}} e^{\left\{\int_{0}^{t}\left(\frac{\beta\left(\alpha\left(Z_{t}\right)-\rho\left(Z_{t}\right)\right)}{\rho\left(Z_{t}\right)} F\left(Z_{\tau}\right)^{\left.-\frac{\rho\left(Z_{t}\right)}{\alpha\left(Z_{t}\right)}-\frac{\beta \alpha\left(Z_{t}\right)}{\rho\left(Z_{t}\right)}\right) d \tau}\right\}\right.}
$$


Applying Itô's lemma to obtain $r_{f}(Z)=-\frac{E_{t} \frac{d \xi_{t}}{d t}}{\xi_{t-}}$ yields

$$
\begin{aligned}
r_{f}(Z)= & \frac{\beta \alpha\left(Z_{t}\right)}{\rho\left(Z_{t}\right)}-\frac{\beta\left(\alpha\left(Z_{t}\right)-\rho\left(Z_{t}\right)\right)}{\rho\left(Z_{t}\right)} F(Z)^{-\frac{\rho}{\alpha}}-\left(\alpha\left(Z_{t}\right)-1\right) \theta(Z) \\
& -\sum_{Z^{\prime} \neq Z} \lambda_{Z Z^{\prime}}\left(\left(\frac{F\left(Z^{\prime}\right)}{F(Z)}\right)^{1-\frac{\rho\left(Z_{t}\right)}{\alpha\left(Z_{t}\right)}}-1\right)
\end{aligned}
$$

and

$$
\frac{d \xi_{t}}{\xi_{t-}}=-r_{f}\left(Z_{t-}\right) d t+\sum_{Z^{\prime} \neq Z_{t-}}\left(e^{\phi\left(Z_{t-}, Z^{\prime}\right)}-1\right)\left(d N_{t}\left(Z_{t-}, Z^{\prime}\right)-\lambda_{Z_{t-} Z^{\prime}} d t\right)
$$

where $N_{t}\left(Z, Z^{\prime}\right)$ is a counting process that keeps track of the number of Markov chain jumps from state $Z$ to state $Z^{\prime}$, and $\phi\left(Z, Z^{\prime}\right)$ is defined as follows:

$$
\phi\left(Z, Z^{\prime}\right) \equiv\left(1-\frac{\rho(Z)}{\alpha(Z)}\right) \log \left(\frac{F\left(Z^{\prime}\right)}{F(Z)}\right)
$$

\section{B.2. Proof of Proposition 2}

In the states $(z, Z) \in \Omega_{g}$, the firm's equity value is given by

$$
V\left(z_{t}, Z_{t}\right)=\max _{\left\{\tau^{*}\right\}} E_{t}\left[\int_{t}^{\tau^{*}} \frac{\xi\left(Z_{\tau}\right)}{\xi\left(Z_{t}\right)}\left(X\left(z_{\tau}\right)-c\right) d \tau\right]=v\left(z_{t}, Z_{t}\right)^{+}
$$

The corresponding HJB equation implies that the function $v(z, Z)$ solves the following system of equations for all $(z, Z) \in \Omega_{g}$ :

$$
\begin{aligned}
0= & X(z)-c-r_{f}(Z) v(z, Z)+\sum_{\left(z^{\prime}, Z\right) \in \Omega_{g} \backslash(z, Z)} \lambda_{z z^{\prime}}(Z)\left(v\left(z^{\prime}, Z\right)^{+}-v(z, Z)\right) \\
& +\sum_{Z^{\prime} \neq Z} \lambda(Z) e^{\phi\left(Z, Z^{\prime}\right)}\left(v\left(z, Z^{\prime}\right)^{+}-v(z, Z)\right) .
\end{aligned}
$$

\section{B.3. Equity Value in Solvent and Illiquid States $\left(i_{g}, Z\right)$}

The firm's equity value in states $\left(i_{g}, Z\right)$ is given by

$$
V\left(i_{g}, Z_{t}\right)=\max _{\tau^{*}} E_{t}\left[\int_{t}^{\tau^{*}} \frac{\xi\left(Z_{\tau}\right)}{\xi\left(Z_{t}\right)}\left(X\left(z_{\tau}\right)-c\right) d \tau\right]
$$


The corresponding HJB equation implies that the function $V\left(i_{g}, Z\right)$ solves the following system of equations for all $Z$ :

$$
\begin{aligned}
0= & x-c-r_{f}(Z) V\left(i_{g}, Z\right)+\sum_{\left(z^{\prime}, Z\right) \in \Omega_{g}} \lambda_{i_{g}, z^{\prime}}(Z)\left(V\left(z^{\prime}, Z\right)-V\left(i_{g}, Z\right)\right) \\
& +\sum_{Z^{\prime} \neq Z} \lambda(Z) e^{\phi\left(Z, Z^{\prime}\right)}\left(V\left(i_{g}, Z^{\prime}\right)-V\left(i_{g}, Z\right)\right)
\end{aligned}
$$

\section{B.4. Proof of Proposition 3}

Absent active investor involvement, the firm's equity value in the illiquid state is given by

$$
V^{R}\left(\pi_{t}, Z_{t}\right)=\max _{\left\{\tau^{*}\right\}} E_{t}\left[\int_{t}^{\tau^{*}} \frac{\xi\left(Z_{\tau}\right)}{\xi\left(Z_{t}\right)}\left(X\left(z_{\tau}\right)-c\right) d \tau\right]=v^{R}\left(\pi_{t}, Z_{t}\right)^{+} .
$$

The corresponding HJB equation yields the following set of ODEs that the function function $v^{R}(\pi, Z)$ solves for $Z \in\{G, B\}$ :

$$
\begin{aligned}
0= & x-c-r_{f}(Z) v^{R}(\pi, Z)+v_{\pi}^{R}(\pi, Z) \varpi(Z)(1-\pi) \pi \\
& +\sum_{\left(z^{\prime}, Z\right) \in \Omega_{g}} \pi \lambda_{i_{g}, z^{\prime}}(Z)\left(V\left(z^{\prime}, Z\right)-v^{R}(\pi, Z)\right) \\
& -\sum_{\left(z^{\prime}, Z\right) \in \Omega_{b}}(1-\pi) \lambda_{i_{b}, z^{\prime}}(Z) v^{R}(\pi, Z) \\
& +\sum_{Z^{\prime} \neq Z} \lambda(Z) e^{\phi\left(Z, Z^{\prime}\right)}\left(v^{R}\left(\pi, Z^{\prime}\right) \mathbf{1}_{\left\{\pi \geq \pi^{R}\left(Z^{\prime}\right)\right\}}-v^{R}(\pi, Z)\right) .
\end{aligned}
$$

In states $Z$ for which $\varpi(Z)<0$, the following conditions are satisfied at $\pi^{R}(Z): 0=$ $v_{\pi}^{R}\left(\pi^{R}(Z), Z\right), 0=v^{R}\left(\pi^{R}(Z), Z\right)$. If $\varpi(Z)>0, \pi^{R}(Z)$ is set such that $v^{R}\left(\pi^{R}(Z), Z\right)=$ 0 and $\lim _{\pi \uparrow 1} v^{R}(\pi, Z)=V\left(i_{g}, Z\right)$. If $\varpi(Z)=0$, then the ODE for state $Z$ simplifies to a nonlinear equation.

Boundary Conditions. If $\varpi(Z)<0$ in state $Z$, then $v^{R}\left(\pi_{t}, Z\right)$ satisfies the smooth pasting and value matching conditions,

$$
\begin{aligned}
& 0=\varpi(Z) \cdot\left(1-\pi^{R *}(Z)\right) \cdot \pi^{R *}(Z) \cdot v_{\pi}^{R}\left(\pi^{R *}(Z), Z\right), \\
& 0=v^{R}\left(\pi^{R *}(Z), Z\right) .
\end{aligned}
$$


If $\varpi(Z)>0$, then $\pi^{R *}(Z)$ has to be chosen such that $v^{R}\left(\pi^{R *}(Z), Z\right)=0$ and $v^{R}(1, Z)$ matches $V\left(i_{g}, Z\right)$. If $\varpi(Z)=0$, then the ODE for state $Z$ simplifies to a nonlinear equation. To verify these boundary conditions, let $\bar{V}^{R}\left(\pi_{t}, Z_{t}, \tau^{R}\right)$ denote the equity value given beliefs $\pi_{t}$, aggregate state $Z_{t}$, and given that the agent follows a strategy of abandoning the firm at time $t+\tau^{R}$ if no jump to any other state occurs in the time between $t$ and $t+\tau^{R}$. The first-order necessary condition for $\tau^{R}$ yields

$$
\left.\frac{\partial \bar{V}^{R}\left(\pi_{t}, Z_{t}, \tau^{R}\right)}{\partial \tau^{R}}\right|_{\tau^{R}=\tau^{R *}}=0
$$

A change in variables yields alternatively

$$
\left.\left(\frac{\partial \tilde{V}^{R}\left(\pi_{t}, Z_{t}, \pi^{R}\right)}{\partial \pi^{R}} \cdot \frac{d \pi^{R}\left(\tau^{R}, \pi_{t}, Z_{t}\right)}{d \tau^{R}}\right)\right|_{\tau^{R=\tau^{R *}}}=0
$$

where I define the function $\pi^{R}\left(\tau^{R}, \pi_{t}, Z_{t}\right)$ as follows:

$$
\pi^{R}\left(\tau^{R}, \pi_{t}, Z_{t}\right)=\left(1+e^{\left(-\tau_{Z_{t}}^{R} \cdot \varpi\left(Z_{t}\right)\right)} \cdot \frac{1-\pi_{t}}{\pi_{t}}\right)^{-1}
$$

implying that for all $\pi_{t} \in(0,1)$ we have $\frac{d \pi^{R}}{d \tau^{R}}>0$. Thus, for $\pi_{t} \in(0,1)$ the first-order necessary condition may also be written as

$$
\left.\frac{\partial \tilde{V}^{R}\left(\pi_{t}, Z_{t}, \pi^{R}\right)}{\partial \pi^{R}}\right|_{\pi^{R}=\pi^{R *}\left(Z_{t}\right)}=0
$$

where I define

$$
\pi^{R *}\left(Z_{t}\right) \equiv \pi^{R}\left(\tau^{R *}, \pi_{t}, Z_{t}\right)
$$

Notice that for $\varpi(Z)>0$, any $\tau^{R} \geq 0$ will correspond to $\pi^{R} \geq \pi_{t}$, since waiting time $\tau^{R}$ increases the conditional probability $\pi_{t}$. Let $V^{R}\left(\pi_{t}, Z_{t}\right)$ denote the value function from the optimal solution of the equity holders' problem. Given the assumption that the equity value is strictly positive at $\pi_{t}$, i.e. $V^{R}\left(\pi_{t}, Z_{t}\right)>0$, we obtain

$$
V^{R}\left(\pi^{R}\left(\tau^{R}, \pi_{t}, Z_{t}\right), Z_{t}\right) \geq V^{R}\left(\pi_{t}, Z_{t}\right)>0, \text { for all } \tau^{R} \geq 0
$$

given that $\frac{\partial V^{R}\left(\pi, Z_{t}\right)}{\partial \pi} \geq 0$ for all $\pi \in\left[\pi_{t}, 1\right]$, since $\pi^{R}\left(\tau^{R}, \pi_{t}, Z_{t}\right) \geq \pi_{t}$ for all $\tau^{R} \geq 0$. $\frac{\partial V^{R}\left(\pi, Z_{t}\right)}{\partial \pi} \geq 0$ follows from the assumption that $V\left(i_{g}, Z_{t}\right)>V\left(i_{b}, Z_{t}\right)=0$. Thus, given that $V^{R}\left(\pi_{t}, Z_{t}\right)>0$ and $\varpi(Z)>0$, the equity value after any positive waiting time is 
also positive, and thus it is optimal not to abandon the firm as long as it stays in the current state, that is, it is optimal to set $\tau^{R *}=\infty$. Since

$$
\lim _{\tau^{R} \rightarrow \infty} \pi^{R}\left(\tau^{R}, \pi_{t}, Z_{t}\right)=1
$$

the ODE simplifies in the limit $\tau^{R} \rightarrow \infty$ to the non-linear equation that the function $V\left(i_{g}, Z_{t}\right)$ solves, implying that

$$
\lim _{\pi \rightarrow 1} V^{R}\left(\pi_{t}, Z_{t}\right)=V\left(i_{g}, Z_{t}\right)
$$

On the other hand, for $\varpi(Z)<0$, it follows that $\frac{d \pi^{R}}{d \tau^{R}}<0$, implying that waiting time corresponds to lower conditional probabilities $\pi_{t}$. By assumption, at $\pi=0$ the equity value is zero $\left(V\left(i_{b}, Z\right)=0\right)$, and the firm is abandoned. Further, by assumption, we have $V^{R}(1, Z)=V\left(i_{g}, Z\right)>0$. It is optimal to abandon at $\pi^{R *}$ where $\pi^{R *}$ satisfies

$$
V^{R}\left(\pi^{R *}, Z\right)=0
$$

and where the smooth pasting condition

$$
\left.\frac{\partial V^{R}\left(\pi, Z_{t}\right)}{\partial \pi}\right|_{\pi_{t}=\pi^{R *}}=0,
$$

is satisfied. If smooth pasting was not satisfied then there could be an optimal cutoff $\pi^{R^{\wedge}}$ where the resulting value function $V^{R^{\wedge}}$ satisfies $V^{R^{\wedge}}\left(\pi^{R^{\wedge}}, Z\right)=0$ and

$$
\left.\frac{\partial V^{R^{\wedge}}\left(\pi, Z_{t}\right)}{\partial \pi}\right|_{\pi_{t}=\pi^{R^{\wedge}}}>0
$$

Yet, then heuristically, at $\pi_{t}=\pi^{R^{\wedge}}$, the agent benefits from waiting another instant $\Delta t$ 
and abandoning the firm afterwards, since the expected income flow is positive:

$$
\begin{aligned}
& \left(x-c+\sum_{z^{\prime} \in \Omega_{g}} \pi(t) \cdot \lambda_{i_{g}, z^{\prime}}(Z) \cdot V\left(z^{\prime}, Z\right)\right) \cdot \Delta t \\
+ & \sum_{z^{\prime} \in \Omega_{b}}(1-\pi(t)) \cdot \lambda_{i_{b}, z^{\prime}}(Z) \cdot V\left(z^{\prime}, Z\right) \cdot \Delta t \\
& +\sum_{Z^{\prime} \neq Z} \lambda(Z) \cdot\left(1-\kappa\left(Z, Z^{\prime}\right)\right) \cdot v^{R}\left(\pi_{t}, Z^{\prime}\right)^{+} \cdot \Delta t \\
= & -V_{\pi}^{R^{\wedge}}\left(\pi_{t}, Z\right) \frac{d \pi_{t}}{d t} \cdot \Delta t \\
> & 0 .
\end{aligned}
$$

This contradicts that $\pi^{R^{\wedge}}$ is an optimal cutoff. Since $\left.\frac{\partial V^{R^{\wedge}}\left(\pi, Z_{t}\right)}{\partial \pi}\right|_{\pi_{t}=\pi^{R^{\wedge}}}>0$ violates optimization and since $\frac{\partial V^{R}\left(\pi, Z_{t}\right)}{\partial \pi}$ is weakly positive over the whole domain $\pi \in[0,1]$, it follows that $\left.\frac{\partial V^{R^{\wedge}}\left(\pi, Z_{t}\right)}{\partial \pi}\right|_{\pi_{t}=\pi^{R *}(Z)}=0$ must hold at the optimal cutoff $\pi^{R *}(Z)$, given that $\varpi(Z)<0$.

\section{B.5. Proof of Proposition 4}

In the initial liquid states $(z, Z) \in \Omega_{l}$ the firm's equity value is given by

$$
V\left(z_{t}, Z_{t}\right)=\max _{\left\{\tau^{*}\right\}} E_{t}\left[\int_{t}^{\tau^{*}} \frac{\xi\left(Z_{\tau}\right)}{\xi\left(Z_{t}\right)}\left(\left(X\left(z_{\tau}\right)-c\right) d \tau\right)\right],
$$

The corresponding HJB equation implies that the function $V(z, Z)$ solves the following system of equations for all $(z, Z) \in \Omega_{l}$ :

$$
\begin{aligned}
0= & X(z)-c-r_{f}(Z) V(z, Z)+\left(V^{R}\left(\pi_{0}(Z), Z\right)-V(z, Z)\right) \sum_{\left(z^{\prime}, Z\right) \in \Omega_{i}} \lambda_{z z^{\prime}}(Z) \\
& +\sum_{\left(z^{\prime}, Z\right) \in \Omega_{l} \backslash(z, Z)} \lambda_{z z^{\prime}}(Z)\left(V\left(z^{\prime}, Z\right)-V(z, Z)\right) \\
& +\sum_{Z^{\prime} \neq Z} \lambda(Z) e^{\phi\left(Z, Z^{\prime}\right)}\left(V\left(z, Z^{\prime}\right)-V(z, Z)\right) .
\end{aligned}
$$




\section{B.6. Proof of Proposition 5}

In the illiquid state, the active investor's value from its exposure to the firm is given by

$$
\begin{aligned}
V^{A}\left(\pi_{t}, Z_{t}, \kappa_{t}\right) & =\max _{\left\{\tau^{*}, a\right\}} E_{t}\left[\int_{t}^{\tau^{*}} \frac{\xi\left(Z_{\tau}\right)}{\xi\left(Z_{t}\right)}\left(\omega\left(X\left(z_{\tau}\right)-c\right)-a_{t} \chi\right) d \tau+\frac{\xi\left(Z_{\tau^{*}}\right)}{\xi\left(Z_{t}\right)} \omega \kappa_{\tau^{*}}\right] \\
& =v^{A}\left(\pi_{t}, Z_{t}\right)^{+}+\omega \kappa_{t} .
\end{aligned}
$$

The corresponding HJB equation yields the following set of ODEs that the function $v^{A}(\pi, Z)$ solves for $Z \in\{G, B\}$ :

$$
\begin{aligned}
0= & \omega(x-c)-a(\pi, Z) \chi-r_{f}(Z) v^{A}(\pi, Z)+v_{\pi}^{A}(\pi, Z) \varpi(Z)(1-\pi) \pi \\
& +\sum_{\left(z^{\prime}, Z\right) \in \Omega_{g}} \pi \lambda_{i_{g}, z^{\prime}}(Z)\left(\omega V\left(z^{\prime}, Z\right)-v^{A}(\pi, Z)\right)-\sum_{\left(z^{\prime}, Z\right) \in \Omega_{b}}(1-\pi) \lambda_{i_{b}, z^{\prime}}(Z) v^{A}(\pi, Z) \\
& \left.+a(\pi, Z)^{1-\eta}\left(\pi \omega V\left(i_{g}, Z\right)-v^{A}(\pi, Z)\right)\right) \\
& +\sum_{Z^{\prime} \neq Z} \lambda(Z) e^{\phi\left(Z, Z^{\prime}\right)}\left(v^{A}\left(\pi, Z^{\prime}\right) \mathbf{1}_{\left\{\pi>\pi^{A}\left(Z^{\prime}\right)\right\}}-v^{A}(\pi, Z)\right)
\end{aligned}
$$

The first order necessary condition for $a_{t}$ yields

$$
\left.a(\pi, Z)=\left(\frac{1-\eta}{\chi}\left(\pi \omega V\left(i_{g}, Z\right)-v^{A}(\pi, Z)\right)\right)\right)^{\frac{1}{\eta}}, \text { for } \pi>\pi^{A}(Z)
$$

In states $Z$ for which $\varpi(Z)<0$, the following conditions are satisfied at $\pi^{A}(Z)$ : $0=$ $v_{\pi}^{A}\left(\pi^{A}(Z), Z_{t}\right), 0=v^{A}\left(\pi^{A}(Z), Z_{t}\right)$. If $\varpi(Z)>0$ for all $Z \in\{G, B\}$, then $\pi^{A}(Z)$ is set such that $v^{A}\left(\pi^{A}(Z), Z\right)=0$ and $\lim _{\pi \uparrow 1} v^{A}(\pi, Z)=\omega V\left(i_{g}, Z\right)$. If $\varpi(Z)=0$, then the ODE simplifies to a nonlinear equation.

Boundary Conditions. As in proposition 3, smooth pasting and value matching applies in aggregate states $Z$ for which $\varpi(Z)<0$,

$$
\begin{aligned}
& 0=\varpi(Z)\left(1-\pi^{A *}(Z)\right) \cdot \pi^{A *}(Z) \cdot v_{\pi}^{A}\left(\pi^{A *}(Z), Z_{t}\right) \\
& 0=v^{A}\left(\pi^{A *}(Z), Z_{t}\right)
\end{aligned}
$$

If $\varpi(Z)>0$, then $\pi^{A *}(Z)$ has to be chosen such that $v^{A}\left(\pi^{A *}(Z), Z\right)=0$ and $v^{A}(1, Z)$ matches $\omega V\left(i_{g}, Z\right)$. If $\varpi(Z)=0$, then the ODE simplifies to a nonlinear equation. 


\section{B.7. Proof of Proposition 6}

The firm's equity value in the illiquid state is given by

$$
\begin{aligned}
V\left(\pi_{t}, Z_{t}, \kappa_{t}\right) & =\max _{\tau^{*}} E_{t}\left[\int_{t}^{\tau^{*}} \frac{\xi\left(Z_{\tau}\right)}{\xi\left(Z_{t}\right)}\left(\left(X\left(z_{\tau}\right)-c\right) d \tau\right)+\frac{\xi\left(Z_{\tau^{*}}\right)}{\xi\left(Z_{t}\right)} \kappa_{\tau^{*}}\right] \\
& =v\left(\pi_{t}, Z_{t}\right)^{+}+\kappa_{t}
\end{aligned}
$$

The corresponding HJB equation yields the following set of ODEs that the function $v(\pi, Z)$ solves for $Z \in\{G, B\}$ :

$$
\begin{aligned}
0= & x-c-r_{f}(Z) v(\pi, Z)+v_{\pi}(\pi, Z) \varpi(Z)(1-\pi) \pi \\
& +\sum_{\left(z^{\prime}, Z\right) \in \Omega_{g}} \pi \lambda_{i_{g}, z^{\prime}}(Z)\left(V\left(z^{\prime}, Z\right)-v(\pi, Z)\right) \\
& -\sum_{\left(z^{\prime}, Z\right) \in \Omega_{b}}(1-\pi) \lambda_{i_{b}, z^{\prime}}(Z) v(\pi, Z) \\
& \left.+a(\pi, Z)^{1-\eta}\left(\pi V\left(i_{g}, Z\right)-v(\pi, Z)\right)\right) \\
& +\sum_{Z^{\prime} \neq Z} \lambda(Z) e^{\phi\left(Z, Z^{\prime}\right)}\left(v\left(\pi, Z^{\prime}\right) \mathbf{1}_{\left\{\pi \geq \pi^{*}\left(Z^{\prime}\right)\right\}}-v(\pi, Z)\right),
\end{aligned}
$$

where $a$ is the optimal solution to the active investor's problem and where $\pi^{*}(Z)=$ $\pi^{A}(Z)$. In states $Z$ for which $\varpi(Z)<0$, we have the condition $\lim _{\pi \downarrow \pi^{*}(Z)} v(\pi, Z)=0$. If $\varpi(Z)>0$, then $\lim _{\pi \uparrow 1} v(\pi, Z)=V\left(i_{g}, Z\right)$. If $\varpi(Z)=0$, then the ODE simplifies to a nonlinear equation.

Equity holders take the active investor's optimal decisions $\left(a_{t}\right.$ and $\left.\pi^{A}(Z)\right)$ as given. The active investor optimally reveals information as soon as she obtains information. Information revelation through the active investor is thus independent of the underlying firm state $\left(i_{g}\right.$ vs. $\left.i_{b}\right)$ and thus does not alter the evolution of beliefs absent signals (that is, $\varpi(Z)$ is identical to the case without active investor).

Boundary Conditions (Case $1 \varpi(Z)<0$ ): For states $Z$ with $\varpi(Z)<0$, the function $v(\pi, Z)$ matches a value of zero at $\pi=\pi^{A *}$, that is $v\left(\pi^{A *}, Z\right)=0$ (smooth pasting holds as well $\left.\frac{\partial v(\pi, Z)}{\partial \pi}\right|_{\pi=\pi^{A *}}=0$. At $\pi=\pi^{A *}$, the active investor abandons the firm, implying that the equity holders are left with the reservation value $V^{R}(\pi, Z)$. Since the active investor's value is naturally bounded from below by the value of its equity position under a passive strategy $\left(a_{t}=0\right)$, optimization implies the relation $V^{A}(\pi, Z) \geq$ $\omega V^{R}(\pi, Z)$. Since $\frac{\partial V^{A}(\pi, Z)}{\partial \pi} \geq 0$ and $\frac{\partial V^{R}(\pi, Z)}{\partial \pi} \geq 0$, it is also the case that the active 
investor's optimal abandonment cutoff $\pi^{A *}(Z)$ is weakly lower than the equity holders' optimal reservation value cutoff, that is, $\pi^{A *}(Z) \leq \pi^{R *}(Z)$. The equity value absent active investor involvement, $V^{R}$, has to be equal to be zero at $\pi(t)=\pi^{A *}(Z)$ since the active investor value $V^{A}(\pi, Z)$ is zero, and $\omega V^{R}(\pi, Z) \leq V^{A}(\pi, Z)$. For $\pi(t)>\pi^{A *}(Z)$, it be that $V\left(\pi_{t}, Z_{t}\right)>0$, since $V^{A}(\pi, Z)>0$ and passive equity holders obtain the same benefits as the active investor from holding the equity (up to the scaling factor $\omega$ ), but do not bear the flow cost of information acquisition going forward. The smooth pasting condition

$$
\lim _{\pi_{t} \downarrow \pi^{A *}(Z)} V_{\pi}\left(\pi, Z_{t}\right)=\lim _{\pi_{t} \uparrow^{A *}(Z)} V_{\pi}\left(\pi, Z_{t}\right)=0,
$$

applies at $\pi_{t}=\pi^{A *}(Z)$. If it were the case that $\left.V_{\pi}\left(\pi, Z_{t}\right)\right|_{\pi_{t}=\pi^{A *}(Z)}>0$, and $v\left(\pi_{t}, Z\right)=0$, then equity holders would benefit from waiting for another instant since active investor abandonment implies $a_{t}=0$, implying equity holders would obtain the positive flow

$$
\begin{aligned}
& \left(x-c+\sum_{z^{\prime} \in \Omega_{g}} \pi(t) \lambda_{i_{g}, z^{\prime}}(Z)\left(V\left(z^{\prime}, Z\right)\right)\right) \cdot \Delta t \\
+ & \sum_{z^{\prime} \in \Omega_{b}}(1-\pi(t)) \lambda_{i_{b}, z^{\prime}}(Z)\left(V\left(z^{\prime}, Z\right)\right) \cdot \Delta t \\
& +\sum_{Z^{\prime} \neq Z} \lambda(Z)\left(1-\kappa\left(Z, Z^{\prime}\right)\right)\left(v\left(\pi_{t}, Z^{\prime}\right)^{+}\right) \cdot \Delta t . \\
= & -v_{\pi}\left(\pi^{A *}(Z), Z\right) \frac{d \pi_{t}}{d t} \cdot \Delta t \\
> & 0 .
\end{aligned}
$$

Yet this would imply that $\pi=\pi^{A *}(Z)$ is not an optimal cutoff. $\pi^{A *}(Z)$ is thus not an optimal abandonment cutoff for equity holders unless $V\left(\pi^{A *}(Z), Z\right)=0$, and $\left.V_{\pi}\left(\pi, Z_{t}\right)\right|_{\pi_{t}=\pi^{A *}(Z)}>0$.

Boundary Conditions (Case $2 \varpi(Z)>0$ ): For $\varpi(Z)>0$, then $v(1, Z)$ matches the value $V\left(i_{g}, Z\right)$. If $\varpi(Z)=0$, then the ODE simplifies to a nonlinear equation. The value function for state $Z$, denoted by $v(\pi, Z)$, generally jumps discontinuously from zero to a positive value at $\pi=\pi^{A *}(Z)$. By definition, the value of the active investor's position at $\pi=\pi^{A *}(Z)$ zero, that is, $V^{A}\left(\pi^{A *}(Z), Z\right)=0$. If the active investor has not abandoned the firm yet, it must be that the equity value is strictly positive, that is, $V\left(\pi^{A *}(Z), Z\right)>0$, since equity holders obtain the same benefits as the active investor from holding the equity (up to the scaling factor $\omega$ ), but do not bear the flow cost of information acquisition going forward. Thus, $\omega V\left(\pi^{A *}(Z), Z\right)>V^{A}\left(\pi^{A *}(Z), Z\right)=0$. 


\section{References}

ABEL, A. B. (1999): "Risk premia and term premia in general equilibrium," Journal of Monetary Economics, 43(1), 3-33.

Avramov, D., T. Chordia, G. Jostova, and A. Philipov (2007): "Momentum and Credit Rating," Journal of Finance, 62(5), 2503-2520.

Bansal, R., And A. Yaron (2004): "Risks for the Long Run: A Potential Resolution of Asset Pricing Puzzles," Journal of Finance, 59(4), 1481-1509.

Bhamra, H. S., L.-A. Kuehn, And I. A. Strebulaev (2010): "The Aggregate Dynamics of Capital Structure and Macroeconomic Risk," Review of Financial Studies, $23(12), 4187-4241$.

Boguth, O., M. Carlson, A. Fisher, And M. Simutin (2011): "Conditional risk and performance evaluation: Volatility timing, overconditioning, and new estimates of momentum alphas," Journal of Financial Economics, 102(2), 363 - 389.

Brophy, D. J., P. P. Ouimet, and C. Sialm (2009): "Hedge Funds as Investors of Last Resort?," Review of Financial Studies, 22(2), 541-574.

Campbell, J. Y., J. Hilscher, and J. Szilagyi (2008): "In Search of Distress Risk," Journal of Finance, 63(6), 2899-2939.

Chen, H. (2010): "Macroeconomic Conditions and the Puzzles of Credit Spreads and Capital Structure," Journal of Finance, 65(6), 2171-2212.

DA, Z., And P. GaO (2010): "Clientele Change, Liquidity Shock, and the Return on Financially Distressed Stocks," Journal of Financial and Quantitative Analysis, 45(01), 27-48.

DAVID, A. (2008): "Inflation Uncertainty, Asset Valuations, and the Credit Spreads Puzzle," 21(6), 2487-2534.

Dichev, I. D. (1998): "Is the Risk of Bankruptcy a Systematic Risk?," Journal of Finance, 53(3), 1131-1147.

Epstein, L. G., And S. E. Zin (1989): "Substitution, Risk Aversion, and the Temporal Behavior of Consumption and Asset Returns: A Theoretical Framework," Econometrica, 57(4), 937-69. 
Gao, P., C. A. Parsons, and J. Shen (2013): "The Global Relation between Financial Distress and Equity Returns," Working paper series, University of California, San Diego (UCSD) - Rady School of Management.

Garlappi, L., T. Shu, and H. Yan (2008): "Default Risk, Shareholder Advantage, and Stock Returns," Review of Financial Studies, 21(6), 2743-2778.

Garlappi, L., And H. YAn (2011): "Financial Distress and the Cross-section of Equity Returns," Journal of Finance, 66(3), 789-822.

George, T. J., And C.-Y. Hwang (2010): "A resolution of the distress risk and leverage puzzles in the cross section of stock returns," Journal of Financial Economics, 96(1), 56-79.

Gomes, J. F., And L. Schmid (2010): "Levered Returns," The Journal of Finance, $65(2), 467-494$.

Grant, D. (1977): "Portfolio Performance and the \&quot;Cost\&quot; of Timing Decisions," Journal of Finance, 32(3), 837-46.

Griffin, J. M., and M. L. Lemmon (2002): "Book-to-Market Equity, Distress Risk, and Stock Returns," Journal of Finance, 57(5), 2317-2336.

Grossman, S. J., and O. D. Hart (1980): "Takeover Bids, the Free-Rider Problem, and the Theory of the Corporation," Bell Journal of Economics, 11(1), 42-64.

Hackbarth, D., R. F. H. Haselmann, and D. Schoenherr (2013): "Financial Distress, Stock Returns, and the 1978 Bankruptcy Reform Act," Working paper series, Boston University School of Management.

Hackbarth, D., J. Miao, and E. Morellec (2006): "Capital structure, credit risk, and macroeconomic conditions," Journal of Financial Economics, 82(3), 519-550.

Hansen, L. P., J. C. Heaton, and N. Li (2008): "Consumption Strikes Back? Measuring Long-Run Risk," Journal of Political Economy, 116(2), 260-302.

Hertzel, M., M. Lemmon, J. S. Linck, And L. Rees (2002): "Long-Run Performance following Private Placements of Equity," Journal of Finance, 57(6), 2595-2617.

Hertzel, M. G., And R. L. Smith (1993): "Market Discounts and Shareholder Gains for Placing Equity Privately," Journal of Finance, 48(2), 459-85. 
Jagannathan, R., and Z. Wang (1996): "The Conditional CAPM and the CrossSection of Expected Returns," Journal of Finance, 51(1), 3-53.

Jensen, M. C., And W. H. Meckling (1976): "Theory of the firm: Managerial behavior, agency costs and ownership structure," Journal of Financial Economics, $3(4), 305-360$.

Johnson, T. C. (2002): "Rational Momentum Effects," Journal of Finance, 57(2), 585-608.

Kreps, D. M., And E. L. Porteus (1978): "Temporal Resolution of Uncertainty and Dynamic Choice Theory," Econometrica, 46(1), 185-200.

Krishnamurthy, S., P. Spindt, V. Subramaniam, and T. Woidtke (2005): "Does investor identity matter in equity issues? Evidence from private placements," Journal of Financial Intermediation, 14(2), 210-238.

Livdan, D., H. Sapriza, And L. Zhang (2009): "Financially Constrained Stock Returns," The Journal of Finance, 64(4), 1827-1862.

McQuade, T. J. (2013): "Stochastic Volatility and Asset Pricing Puzzles," Working paper series, Harvard University.

Melino, A., And A. X. YAng (2003): "State-sdgsdsgdserreds preferences can explain the equity premium puzzle," Review of Economic Dynamics, 6(4), 806 - 830.

Myers, S. C. (1977): "Determinants of corporate borrowing," Journal of Financial Economics, 5(2), 147-175.

O’Doherty, M. S. (2012): "On the Conditional Risk and Performance of Financially Distressed Stocks," Management Science.

Ozdagli, A. (2013): "Distressed, but not risky: Reconciling the empirical relationship between financial distress, market-based risk indicators, and stock returns (and more).," Working paper series, Federal Reserve Bank of Boston.

PARK, J. (2013): "Equity Issuance and Returns to Distressed Firms," Working paper series, Korea University Business School.

Pastor, L., And P. Veronesi (2009): "Learning in Financial Markets," Annual Review of Financial Economics, 1(1), 361-381. 
Sagi, J. S., and M. S. Seasholes (2007): "Firm-specific attributes and the crosssection of momentum," Journal of Financial Economics, 84(2), 389-434.

Schumpeter, J. A. (1934): The Theory of Economic Development. Cambridge, Mass.: Harvard University Press.

Shleifer, A., And R. W. Vishny (1986): "Large Shareholders and Corporate Control," Journal of Political Economy, 94(3), 461-88.

Vassalou, M., And Y. Xing (2004): "Default Risk in Equity Returns," Journal of Finance, 59(2), 831-868.

WEIL, P. (1990): "Nonexpected Utility in Macroeconomics," The Quarterly Journal of Economics, 105(1), 29-42. 